\title{
Synthesis, structural characterisation and theoretical studies of a novel pyridazine derivative: investigations of anti-inflammatory activity and inhibition of $\alpha$-glucosidase
}

Younes Zaoui ${ }^{1}$; Youssef Ramli ${ }^{1 *}$; Sang Loon Tan²; Edward R. T. Tiekink ${ }^{2 *}$; Laila Chemlal ${ }^{3}$; Joel T. Mague ${ }^{4}$; Jamal Taoufik ${ }^{1}$; M.A.Faouzi ${ }^{3}$ and M'Hammed Ansar ${ }^{1}$

${ }^{1}$ Laboratory of Medicinal Chemistry, Drug Sciences Research Center, Faculty of Medicine and Pharmacy, Mohammed V University in Rabat, Rabat, Morocco

${ }^{2}$ Research Centre for Crystalline Materials, School of Medical and Life Sciences, Sunway University, Bandar Sunway 47000, Selangor Darul Ehsan, Malaysia

${ }^{3}$ Laboratories of Pharmacology and Toxicology, Faculty of Medicine and Pharmacy, Mohammed V University in Rabat, Morocco

${ }^{4}$ Department of Chemistry, Tulane University, New Orleans, LA 70118, USA.

*Corresponding authors: y.ramli@um5s.net.ma; edwardt@,sunway.edu.my

\section{Abstract}

X-ray crystallography on pyridazine 1 (ethyl 2-(3-methyl-4-(4-methylbenzyl)-6-oxopyridazin$1(6 \mathrm{H})$-yl)acetate) shows the planar pyridazinyl ring to exhibit significant delocalisation of $\pi$ electron density over the constituent atoms and to be substituted with oxo, methyl, (4methylphenyl)methyl and N-bound ethylacetate groups. While three of the ring-bound atoms are close to co-planar with the ring, the ethylacetate group is not; the latter exhibits a definitive kink in its conformation. In the molecular packing of $\mathbf{1}$, helical supramolecular chains along the b-axis are formed through $\mathrm{O}$ - and $\mathrm{N}$-methylene- $\mathrm{C}-\mathrm{H} \cdots \mathrm{O}$ (carbonyl) and $\mathrm{O}-$ methylene-C- $\mathrm{H}^{\cdots} \pi$ (pyridazinyl) interactions. The chains are connected into a supramolecular layer by $\pi$ (pyridazinyl) $\cdots \pi$ (phenyl) interactions. The flat layers stacks along the c-axis 
without directional interactions between them. The geometry-optimisation of $\mathbf{1}$ resulted in the straightening of terminal ethylacetate group but no other substantial changes. Computational chemistry shows the most stabilising interactions in the crystal are due to the $\pi$ (pyridazinyl) $\cdots \pi$ (phenyl) $\quad(-10.7 \mathrm{kcal} / \mathrm{mol})$ followed by $\mathrm{O}-$ and $\mathrm{N}$-methylene-C$\mathrm{H} \cdots \mathrm{O}$ (carbonyl) (-9.5 and $-9.0 \mathrm{kcal} / \mathrm{mol}$, respectively). The most prominent identified interlayer interaction is a weak methylene-C- $\mathrm{H}^{\cdots} \mathrm{N}$ (pyridazinyl) contact. Throughout, comparisons are made with the phenyl analogue of $\mathbf{1}$, namely $\mathbf{2}$. Most notably, the lattice energy of $\mathbf{1}$ is approximately $4.1 \mathrm{kcal} / \mathrm{mol}$ more stable than that of $\mathbf{2}$, an observation related to the influence upon the molecular packing exerted by the methyl substituent of $\mathbf{1}$. Compound 1 exhibits moderate inhibition against $\alpha$-glucosidase, compared to Acarbose, and weak heatinduced haemolysis inhibition.

Keywords: pyridazinyl; molecular packing; DFT; biological activities

\section{Introduction}

Pyridazine groups are well known as an excellent nitrogen-containing heterocyclic scaffold owing to their extensive pharmacological and biological properties as well as numerous therapeutic applications in medicinal research. Thus, they have been reported to exhibit different activities such as analgesic and anti-inflammatory [1-3], anti-HIV [4], anti-cancer [5], anti-bacterial [6], anti-fungal [7], anti-convulsant [8], cardiotonic [9], anti-ulcer [10] and anti-hypertensive $[11,12]$. Further, they have often been used as a component of a variety of agrochemicals such as insecticides, acaricides [13-15] and herbicides [16,17]. Given the wide range of therapeutic applications for pyridazine derivatives and in continuing interest in the synthesis of heterocyclic systems having remarkable biological potential [18-21], we have already reported a route for the preparation of pyridazine derivatives [22]. In addition to the 
synthesis and spectroscopic characterisation of the new oxo-methylpyridazin derivative containing xylene and ethyl acetate substituents, $\mathbf{1}$, also reported are the molecular and crystal structure of 1 along with a Hirshfeld surface analysis and a density functional theory (DFT) computational study in order to gain a detailed understanding of the crucial intermolecular interactions operating in the crystal of $\mathbf{1}$. Comparisons are made with the phenyl derivative of 1, i.e. 2 , in order to ascertain the influence of the methyl group in 1 upon the molecular packing. Further, based on the wide biological interest of pyridazine derivatives, alluded to above, and due to our continuing interests on the synthesis of heterocyclic systems with remarkable anti-inflammatory and anti-diabetic activities [23-25], 1 was also evaluated for anti-inflammatory and enzyme inhibitory activities using an $\alpha$-Glucosidase inhibition assay.

\section{Experimental section}

1.1. Synthesis and crystallisation of ethyl 2-(3-methyl-4-(4-methylbenzyl)-6-oxopyridazin$1(6 H)$-yl)acetate (1)

All chemicals used were of analytical grade, purchased from commercial suppliers (SigmaAldrich, Merck) and used without further purification. The melting point was obtained on a Büchi Melting Point SMP-20 apparatus and is uncorrected. Infrared (IR) spectra were recorded with an IR VERTEX 70 FT-IR (Bruker Optics) spectrophotometer. Nuclear magnetic resonance $\left({ }^{1} \mathrm{H}\right.$ and ${ }^{13} \mathrm{C}\left\{{ }^{1} \mathrm{H}\right\}$ NMR) spectra were recorded on a BrukerAvance (400 $\mathrm{MHz}$ ) spectrometer, using tetramethylsilane (TMS) as the internal standard and DMSO-d6 as solvent. Mass spectra were recorded on an API 3200 LC/MS/MS mass spectrometer using electrospray ionization (ESI) in positive polarity.

An acetic acid $(50 \mathrm{ml})$ solution of 4-methylbenzaldehyde $(0.01 \mathrm{~mol})$ and levulinic acid $(0.015$ mol) was saturated with dry hydrogen chloride for $4 \mathrm{~h}$ followed by stirring at room 
temperature for $24 \mathrm{~h}$. The solvent was evaporated under reduced pressure and the residue was washed with water and chloroform. To the formed residue, 3-(4-methylbenzylidene)-4oxopentanoic acid $(0.01 \mathrm{~mol})$ taken in ethanol $(20 \mathrm{ml})$ was added hydrazine hydrate $(0.02$ mol) followed by refluxing for $2 \mathrm{~h}$. The precipitate that formed was filtered and recrystallised from ethanol to obtain 6-methyl-5-(4-methylbenzyl)pyridazin-3(2H)-one. In dimethylformamide $(500 \mathrm{ml})$, to this pyridazine $(0.01 \mathrm{~mol})$ was added potassium carbonate $(0.02 \mathrm{mmol})$, tetra-n-butylammonium bromide $(0.001 \mathrm{mmol})$ and 2-ethyl bromoacetate $(0.02$ mol). The mixture was stirred for $24 \mathrm{~h}$ at room temperature. After this, the mixture was filtered and the solvent evaporated under reduced pressure. The residue was washed with water and methylene chloride. The solvent was removed and the residue was crystallised from its acetone solution. The reaction scheme is shown in Scheme 1. Colourless crystals: yield: 77\%; M. pt: $133-135{ }^{\circ} \mathrm{C} . \quad \mathrm{SM}(\mathrm{ESI}+)(\mathrm{m} / \mathrm{z}):[\mathrm{M}+\mathrm{H}]^{+}=301.13 . \quad$ IR $\left(\mathrm{cm}^{-1}\right): 1743.18$ $\left(\mathrm{C}=\mathrm{O}, \mathrm{CO}_{2} \mathrm{Et}\right), 1659.61(\mathrm{C}=\mathrm{ON}), 1598.64(\mathrm{C}=\mathrm{C}), 1204.87(\mathrm{C}-\mathrm{N}), 1010.76$ and $1144.87(\mathrm{C}-\mathrm{O}$, $\mathrm{CO}_{2}$ Et sym and asym). ${ }^{1} \mathrm{H}$ NMR (ppm): 1.23 (t, 3H, $\left.J=7.1, \mathrm{CH}_{2}-\mathrm{CH}_{3}\right) ; 2.22\left(\mathrm{~s}, 3 \mathrm{H}, \mathrm{CH}_{3}-\right.$ Pyridazinone); 2.30 (s, 3H, CH3-phenyl); 3.85 (s, 2H, Phenyl- $\mathrm{CH}_{2}-$ Pyridazinone); 4.17 (q, 2H, $\left.J=7.1, \mathrm{O}-\mathrm{CH}_{2}-\mathrm{CH}_{3}\right) ; 4.87$ (s, 2H, -N-CH $\left.2-\mathrm{CO}\right) ; 6.47$ (s, 1H, Pyridazinone); 7.25-7.47 (m, 4H, $J=3$, Phenyl). ${ }^{13} \mathrm{C}$ NMR (ppm): $14.11\left(\mathrm{CH}_{3}\right) ; 21.03\left(\mathrm{CH}_{3}\right.$, Pyridazinone); $22.03\left(\mathrm{CH}_{3}\right.$, Phenyl); $37.67\left(\mathrm{CH}_{2}\right) ; 51.34\left(\mathrm{CH}_{2}\right) ; 60.95\left(\mathrm{CH}_{2}\right) ; 127.13-127.44(\mathrm{CH}$ aromatic); 129.13$130.35\left(\mathrm{CH}\right.$ aromatic); $132.12\left(\mathrm{C}-\mathrm{C} \alpha\right.$ aromatic); $136.51\left(\mathrm{CH}_{2}-\underline{\mathrm{C}}=\right.$, aromatic); $138.49(\mathrm{CH}$, Pyridazinone); $144.97 \quad\left(\mathrm{CH}_{2}-\underline{\mathrm{C}}=\mathrm{CH}, \quad\right.$ Pyridazinone $) ; 147.17 \quad(\mathrm{C}=\mathrm{N}) ; 161.19 \quad(\mathrm{C}=\mathrm{O}$, Pyridazinone); $169.52\left(\mathrm{C}=\mathrm{O}, \mathrm{CO}_{2} \mathrm{Et}\right) . \quad \mathrm{SM}(\mathrm{ESI}+), \mathrm{IR}$ and NMR spectra are given in the Supplementary Material Tables S1-S4. 

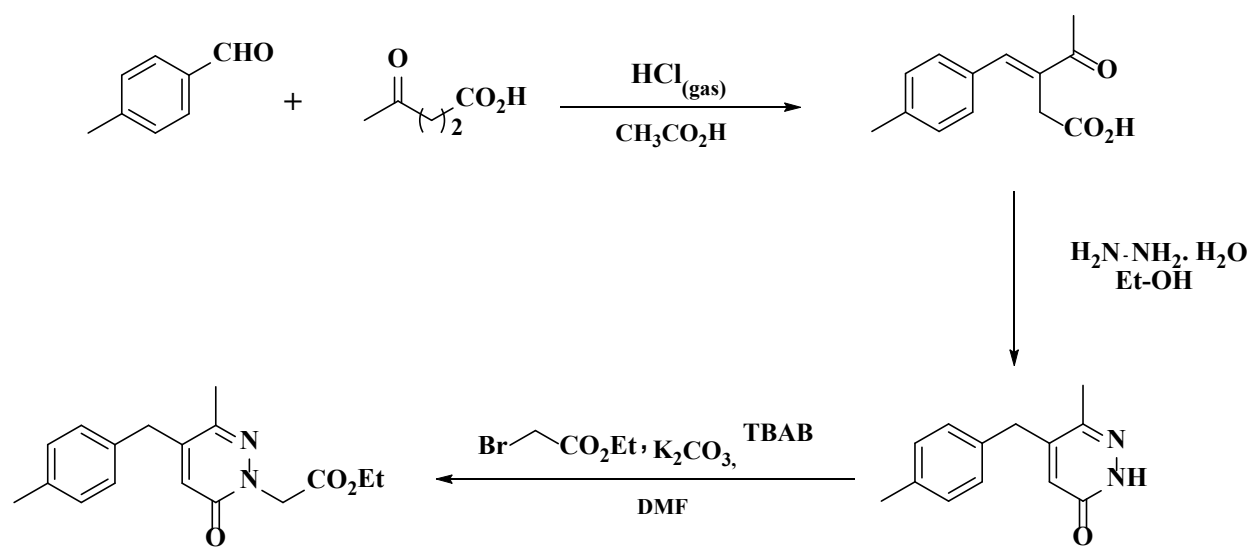

Scheme 1. Synthesis route for 1. Compound 2, also discussed in detail in this study, is the phenyl analogue of $\mathbf{1}$.

\subsection{Single crystal X-ray structure determination}

Crystal data and refinement details are given in Table 1 . Intensity measurements for $\mathbf{1}$ were measured employing APEX3 [23] at $\mathrm{T}=120 \mathrm{~K}$ on a Bruker Smart APEX CCD diffractometer equipped using Mo-K $\alpha$ radiation $(\lambda=0.71073 \AA)$. Data reduction was performed with SAINT [26] and the absorption correction was conducted with SADABS [26]. The structure was solved by direct methods [27] and refined (anisotropic displacement parameters and C-bound $\mathrm{H}$ atoms in the riding model approximation) on $F^{2}$ [28]. A weighting scheme of the form $w=$ $1 /\left[\sigma^{2}\left(F_{\mathrm{o}}^{2}\right)+(0.092 P)^{2}\right]$ where $\left.P=\left(F_{\mathrm{o}}^{2}+2 F_{\mathrm{c}}^{2}\right) / 3\right)$ was introduced. The molecular structure diagram was generated with ORTEP for Windows with 70\% displacement ellipsoids [29] and the molecular packing diagrams with DIAMOND [30]. Additional analysis of the structural data was conducted with PLATON [31].

\section{Table 1}

Crystal and refinement data for $\mathbf{1}$.

Formula

$\mathrm{C}_{17} \mathrm{H}_{20} \mathrm{~N}_{2} \mathrm{O}_{3}$

Molecular weight

300.35 


\begin{tabular}{|c|c|}
\hline Crystal system & monoclinic \\
\hline Space group & $P 2{ }_{1} / n$ \\
\hline$a / \AA$ & $8.6449(4)$ \\
\hline$b / \AA$ & $8.0025(4)$ \\
\hline$c / \AA$ & $22.1359(12)$ \\
\hline$\beta /^{\circ}$ & $99.725(1)$ \\
\hline$V / \AA^{3}$ & $1509.37(13)$ \\
\hline$Z$ & 4 \\
\hline$D_{\mathrm{x}} / \mathrm{g} \mathrm{cm}^{-3}$ & 1.322 \\
\hline$F(000)$ & 640 \\
\hline$\mu / \mathrm{mm}^{-1}$ & 0.091 \\
\hline No. reflections measured & 28193 \\
\hline$\theta_{\max }{ }^{\mathbf{o}}$ & 29.2 \\
\hline No. independent reflections & 4050 \\
\hline No. reflections with $I \geq 2 \sigma(I)$ & 3177 \\
\hline$R$ (obs. data) & 0.046 \\
\hline$w R_{2}$ (all data) & 0.136 \\
\hline
\end{tabular}

CCDC 2035086 contains the supplementary crystallographic data for this paper. These data can be obtained free of charge via http://www.ccdc.cam.ac.uk/conts/retrieving.html (or from the Cambridge Crystallographic Data Centre, 12, Union Road, Cambridge CB2 1EZ, UK; fax: +44 1223336033$)$.

\subsection{Quantum chemical calculations}


The gas-phase geometry optimisation calculations were performed with Gaussian 16 [32] using Stewart's semi-empirical PM7 method [33] followed by the DFT-B3LYP exchangecorrelation functional coupled with Ahlrichs' valence triple-zeta polarization basis sets (def2TZVP) [34] with tight SCF convergence criteria applied. Having established the optimised structures, the NBO analysis [35], molecular electrostatic potential (MEP) and frontier molecular orbital (FMO) energies were computed for the optimised structures using the same basis set and level of theory in which the corresponding outputs were analysed and interpreted through GaussView6 [36]. The condensed Fukui function [37] and relevant dual descriptor [38,39] were calculated using the NPA charges derived from the Gaussian program [32].

\subsection{Computational modelling of intermolecular interactions}

The intermolecular interactions and contacts were analysed through CrystalExplorer17 [40] using the methodologies as described previously [41]. Briefly, the distances of atomic surface points to the nearest nucleus inside $\left(d_{i}\right)$ and outside $\left(d_{e}\right)$ the surface were computed and the resulted normalised contact distances $\left(\mathrm{d}_{\text {norm}}\right)$ were mapped onto the Hirshfeld surface in the range -0.0081 to 1.0105 arbitrary units. Contact distances shorter than the sum of van der Waals radii are highlighted in red, while distances equal to or longer than the sum of van der Waals radii are, respectively, shown in white and blue [42]. The combination of $d_{i}$ and $d_{e}$ in intervals of $0.01 \AA$ resulted in the plotting of two-dimensional fingerprint plots, where different colours on the fingerprint plots represent the probability of occurrence, ranging from blue (few points) to green (moderate) and red (many points) [43]. All hydrogen atom bond lengths were normalised to the standard neutron values prior to the analysis.

Upon the identification of close contacts in the Hirshfeld surface analysis, various qualitative and quantitative computations were then performed to study the strength of all identified 
pairwise interacting molecules. The qualitative analysis was achieved through NCIPLOT [44] by plotting the reduced density gradient as a function of density across the molecules. The computed density derivatives were mapped as iso-surfaces which correspond to any favourable or unfavourable interactions as determined by the sign of the second density Hessian eigenvalue times the density [45]. The program VMD Molecular Graphics Viewer [46] was used to visualise the non-covalent interaction index. As for the quantitative analysis, the interaction energies were computed using the optimised CE-B3LYP/6-31G(d,p) model as available in CrystalExplorer17 [40], in which the corresponding energy was obtained by summing up four energy components comprising the electrostatic (Eele), polarization $\left(\mathrm{E}_{\mathrm{pol}}\right)$, dispersion (Edis) as well as exchange-repulsion (Erep) energies with scale factors of 1.057, $0.740,0.871$ and 0.618 , respectively $[47,48]$. A similar method was applied in the simulation of energy frameworks and calculation of the lattice energy for the crystals. The energy frameworks comprising Eele, $E_{\text {dis }}$ and $E_{\text {total }}$ were generated for a cluster of $2 \times 2 \times 1$ unit-cells with the energy cut-off being set to $1.9 \mathrm{kcal} / \mathrm{mol}$, whereas the lattice energy was calculated for a cluster of molecules within a $25 \AA$ radius from a selected central molecule using equation (1):

$$
E_{\text {lattice }}=1 / 2 \sum E_{\text {total }}^{\mathrm{AB}}
$$

Where $A$ is the central molecule, $B$ are the molecules surrounding $A$, and $R_{A B}$ is the separation of the molecular centroids within a radius of $\mathrm{R}_{\mathrm{AB}}$ defined by the molecular centroids [49].

\subsection{Biological assays}

\subsubsection{Enzyme inhibitory activity: $\alpha$-Glucosidase inhibition assay}


The $\alpha$-glucosidase inhibitory activity was performed in phosphate buffered saline PBS $(0.1 \mathrm{M}$ $\mathrm{KH}_{2} \mathrm{PO}_{4}-\mathrm{K}_{2} \mathrm{HPO}_{4}$, pH 6.7), using 4-nitrophenyl- $\alpha$-D-glucopyranoside ( $\left.\rho N P G\right)$ as the substrate according to the method described by Kee et al. [50], with some modifications. All tested extracts were dissolved in phosphate buffered saline (PBS) to a series of different concentrations. Briefly, a mixture of $150 \mu \mathrm{L}$ of the sample and $100 \mu \mathrm{L}$ of phosphate buffered saline (PBS) containing the enzyme $\alpha$-glucosidase solution $(0.1 \mathrm{U} / \mathrm{mL})$ were incubated at 37 ${ }^{\circ} \mathrm{C}$ for $10 \mathrm{~min}$. Then, $200 \mu \mathrm{L}$ 4-nitrophenyl- $\alpha$-D-glucopyranoside $(1 \mathrm{mM})$ was added to the mixture to initiate the reaction. After further incubation at $37{ }^{\circ} \mathrm{C}$ for $30 \mathrm{~min}, 600 \mu \mathrm{L} \mathrm{Na} \mathrm{CO}_{3}$ $(0.1 \mathrm{M})$ was added and the absorbance was measured at $405 \mathrm{~nm}$ on a UV/vis spectrophotometer.

Two concentrations were tested for 1: 45.0 and $22.5 \mathrm{mM} / 1$. The standard, Acarbose, was used as the positive control.

The results were expressed as percentage inhibition and calculated using the following formula (2):

$$
\text { Inhibition }(\%)=\left[1-\left(\mathrm{A}_{\text {sample }}-\mathrm{Ab}_{\text {sample }}\right) /\left(\mathrm{A}_{\text {control }}-\mathrm{Ab}_{\text {control }}\right)\right] \times 100
$$

where:

- $A_{\text {control }}$ refers to the absorbance of control (enzyme and buffer)

- $\mathrm{A} \mathrm{b}_{\text {control }}$ refers to the absorbance of control blank (buffer without enzyme)

- Asample refers to the absorbance of sample (enzyme and inhibitor)

- $A b_{\text {sample }}$ is the absorbance of sample blank (inhibitor without enzyme)

\subsubsection{In vitro anti-inflammatory study}

Preparation of erythrocyte suspension 
A suspension of erythrocytes was prepared by the method described by Shinde et al. [51] with some modifications.

A sample of fresh whole human blood was obtained from a healthy human volunteer at the National Blood Transfusion Center of Rabat, Morocco, in January 2019. Serological tests were performed and proved negative.

Whole human blood was transferred to heparinised centrifuge tubes, centrifuged at $3000 \mathrm{rpm}$ for $5 \mathrm{~min}$ and the supernatants (plasma and leucocytes) were carefully removed while the packed red blood cell was washed three times with equal volume of normal fresh saline $(0.9 \%$ w/v NaCl).

The volume of the blood was measured and reconstituted as a $40 \%(\mathrm{v} / \mathrm{v})$ suspension with isotonic buffer solution (10 mM sodium phosphate buffer $\mathrm{pH}$ 7.4).

The composition of the buffer solution $(\mathrm{g} / \mathrm{l})$ was $\mathrm{NaH}_{2} \mathrm{PO}_{4}(0.2), \mathrm{Na}_{2} \mathrm{HPO}_{4}(1.15)$ and $\mathrm{NaCl}$ (9.0) [52].

\section{Heat-Induced haemolysis assay}

This test was carried out as described by Okoli et al. [53] and Ranasinghe et al. [54]. The isotonic buffer solutions ( $5 \mathrm{ml}$ ) containing 1000,500 and $250 \mu \mathrm{g} / \mathrm{ml}$ of 1 were put in 5 sets of centrifuge tubes (per concentration). The negative control tubes contained $5 \mathrm{ml}$ of the vehicle and positive control tubes contained $100 \mu \mathrm{g} / \mathrm{ml}$ of Indomethacin in $5 \mathrm{ml}$ total volume. The erythrocyte suspension $(0.05 \mathrm{ml})$ was added to each tube and gently mixed. A pair of the tubes was incubated at $54{ }^{\circ} \mathrm{C}$ for $20 \mathrm{~min}$. in a regulated water bath. At the end of the incubation, the reaction mixture was centrifuged at $1300 \mathrm{~g}$ for $3 \mathrm{~min}$ and the absorbance (OD) of the supernatant measured at $540 \mathrm{~nm}$ [6], using a UV-VIS Spectrophotometer UV-1100.

The level of inhibition of haemolysis was calculated using the following relation (3):

$$
\% \text { inhibition of haemolysis }=[(\mathrm{A} \text { Control }-\mathrm{A} \text { Sample }) / \mathrm{A} \text { Control }] \times 100
$$




\section{Results and Discussion}

\subsection{X-ray crystallography}

The molecular structure of $\mathbf{1}$ is shown in Fig. 1 and comprises a central pyridazinyl ring substituted with oxo, methyl, (4-methylphenyl)methyl and N-bound ethylacetate groups. The six-membered ring is planar, exhibiting a r.m.s. of the fitted atoms of $0.0032 \AA$. Of the four ring-bound substituents, only the $\mathrm{C} 5$ atom of the ethylacetate group lies significantly $[0.1282(16) \AA]$ out of the plane through the pyridazinyl ring. Selected geometric parameters are collated in Table 2. Formally, the $\mathrm{C} 1-\mathrm{N} 2$ and $\mathrm{C} 2-\mathrm{C} 3$ bonds are double-bonds but, the lengthening of these bonds, coupled with the lengthening of the C4-N1 bond, and concomitant shortening of the $\mathrm{N} 1-\mathrm{N} 2, \mathrm{C} 1-\mathrm{C} 2$ and $\mathrm{C} 3-\mathrm{C} 4$ bonds along with the lengthening of the exocyclic $\mathrm{C} 4-\mathrm{O} 1$ bond, compared with standard bond lengths, suggests considerable delocalisation of $\pi$-electron density over the oxopyridazinyl part of the molecule. The pendent 4-tolyl ring lies in a position folded towards and almost orthogonal to the plane of the central with the dihedral angle between the least-squares being $81.92(3)^{\circ}$. Similarly, the carboxylate residue is inclined to the central ring but, to the opposite side, with the $\mathrm{C}_{4} \mathrm{~N}_{2} / \mathrm{CO}_{2}$ dihedral angle $=77.98(9)^{\circ}$. The $\mathrm{C} 6-\mathrm{O} 3-\mathrm{C} 7-\mathrm{C} 8$ torsion angle of $-98.20(11)^{\circ}$ is indicative of an -anti-clinal conformation.

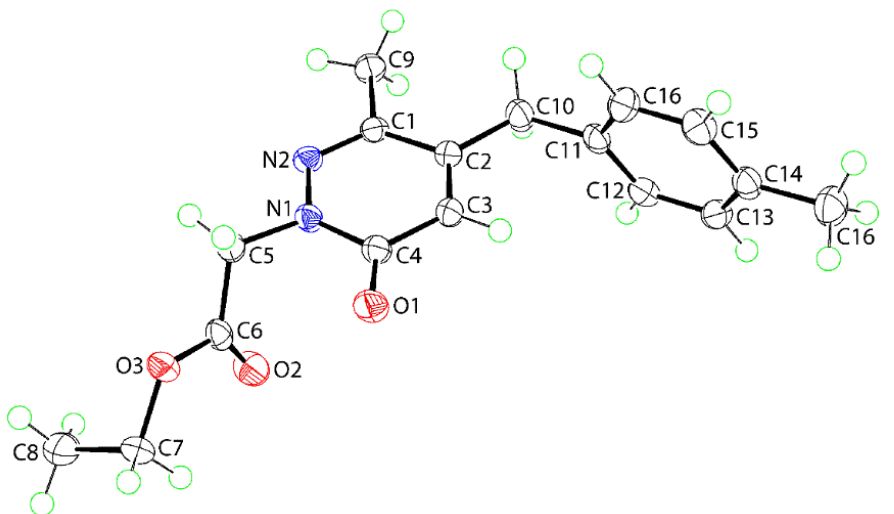

Fig. 1.The molecular structure of $\mathbf{1}$, showing the atom-labelling scheme and displacement ellipsoids at the $70 \%$ probability level. 
Table 2

Selected geometric $\left(\AA,^{\circ}\right)$ parameters for $\mathbf{1}$ and $\mathbf{2}$, as determined by X-ray crystallography, and $1 \mathrm{~g}$ and $\mathbf{2 g}$, from the gas-phase DFT calculations

\begin{tabular}{|c|c|c|c|c|}
\hline Parameter & 1 & $1 \mathrm{~g}$ & 2 & $2 g$ \\
\hline $\mathrm{N} 1-\mathrm{N} 2$ & $1.3645(12)$ & 1.340 & $1.3625(10)$ & 1.339 \\
\hline $\mathrm{C} 1-\mathrm{N} 2$ & $1.3072(14)$ & 1.300 & $1.3063(11)$ & 1.300 \\
\hline $\mathrm{C} 4-\mathrm{N} 1$ & $1.3827(13)$ & 1.400 & $1.3845(12)$ & 1.400 \\
\hline $\mathrm{C} 1-\mathrm{C} 2$ & $1.4434(14)$ & 1.446 & $1.4463(12)$ & 1.446 \\
\hline $\mathrm{C} 2-\mathrm{C} 3$ & $1.3517(15)$ & 1.354 & $1.3535(13)$ & 1.354 \\
\hline $\mathrm{C} 3-\mathrm{C} 4$ & $1.4423(15)$ & 1.445 & $1.4434(12)$ & 1.445 \\
\hline $\mathrm{C} 4-\mathrm{O} 1$ & $1.2354(13)$ & 1.224 & $1.2336(11)$ & 1.224 \\
\hline $\mathrm{C}_{4} \mathrm{~N}_{2} / \mathrm{CO}_{2}$ & 77.98(9) & 88.8 & $77.48(3)$ & 88.6 \\
\hline $\mathrm{C}_{4} \mathrm{~N}_{2} /$ aryl & $81.92(3)$ & 88.7 & $76.94(3)$ & 88.8 \\
\hline $\mathrm{N} 2-\mathrm{N} 1-\mathrm{C} 5-\mathrm{C} 6$ & $120.40(10)$ & 93.0 & $104.33(9)$ & 93.4 \\
\hline $\mathrm{N} 1-\mathrm{C} 5-\mathrm{C} 6-\mathrm{O} 3$ & $154.25(9)$ & 173.3 & $176.15(7)$ & 172.9 \\
\hline $\mathrm{C} 5-\mathrm{C} 6-\mathrm{O} 3-\mathrm{C} 7$ & $174.64(9)$ & 179.6 & $176.99(8)$ & 179.5 \\
\hline $\mathrm{C} 6-\mathrm{O} 3-\mathrm{C} 7-\mathrm{C} 8$ & $-98.20(11)$ & 179.3 & $-172.44(8)$ & 179.2 \\
\hline
\end{tabular}

The closest literature precedent to $\mathbf{1}$ is a species where the 4-tolyl group of $\mathbf{1}$ is now a phenyl group, hereafter 2 [22], see Scheme 1. As seen from Table 2, the key geometric parameters for both molecules are equal within experimental error with any notable differences between the molecules being conformational in nature. Thus, the $\mathrm{C}_{4} \mathrm{~N}_{2} / 4$-tolyl dihedral angle in $\mathbf{1}$ of $81.92(3)^{\circ}$ is wider than the analogous $\mathrm{C}_{4} \mathrm{~N}_{2} /$ phenyl dihedral of $76.94(3)^{\circ}$ in 2 [22]. More dramatic are the differences in the C6-O3-C7-C8 torsion angles of -98.20(11) and - 
$72.44(8)^{\circ}$, respectively, with the latter being indicative of an -anti-periplanar conformation rather than the -anti-clinal conformation observed in $\mathbf{1 .}$

\subsection{Molecular packing}

The key feature of the molecular packing of $\mathbf{1}$ is the formation of supramolecular chains along the b-axis, being propagated by 21 -screw symmetry, Fig. 2(a); details of the identified intermolecular interactions are given in the caption to the figure. The chains feature methylene- $\mathrm{C}-\mathrm{H} \cdots \mathrm{O}$ (carbonyl) interactions with the donor atoms being $\mathrm{O}-$ and $\mathrm{N}$-bound methylene and the acceptor being the ring-carbonyl atom implying this atom is bifurcated. Additional stabilisation to the chain is provided by $\mathrm{O}$-methylene- $\mathrm{C}-\mathrm{H} \cdots \pi$ (pyridazinyl) interactions. The chains are connected into a supramolecular layer parallel to $\left(\begin{array}{lll}-1 & 0 & 1\end{array}\right)$ by $\pi$ (pyridazinyl) $\cdots \pi$ (phenyl) interactions, Fig. 2(b); the layer has a flat topology, Fig. 2(c). The layers stack along the c-axis without directional interactions between them according to the standard distance criteria [31].
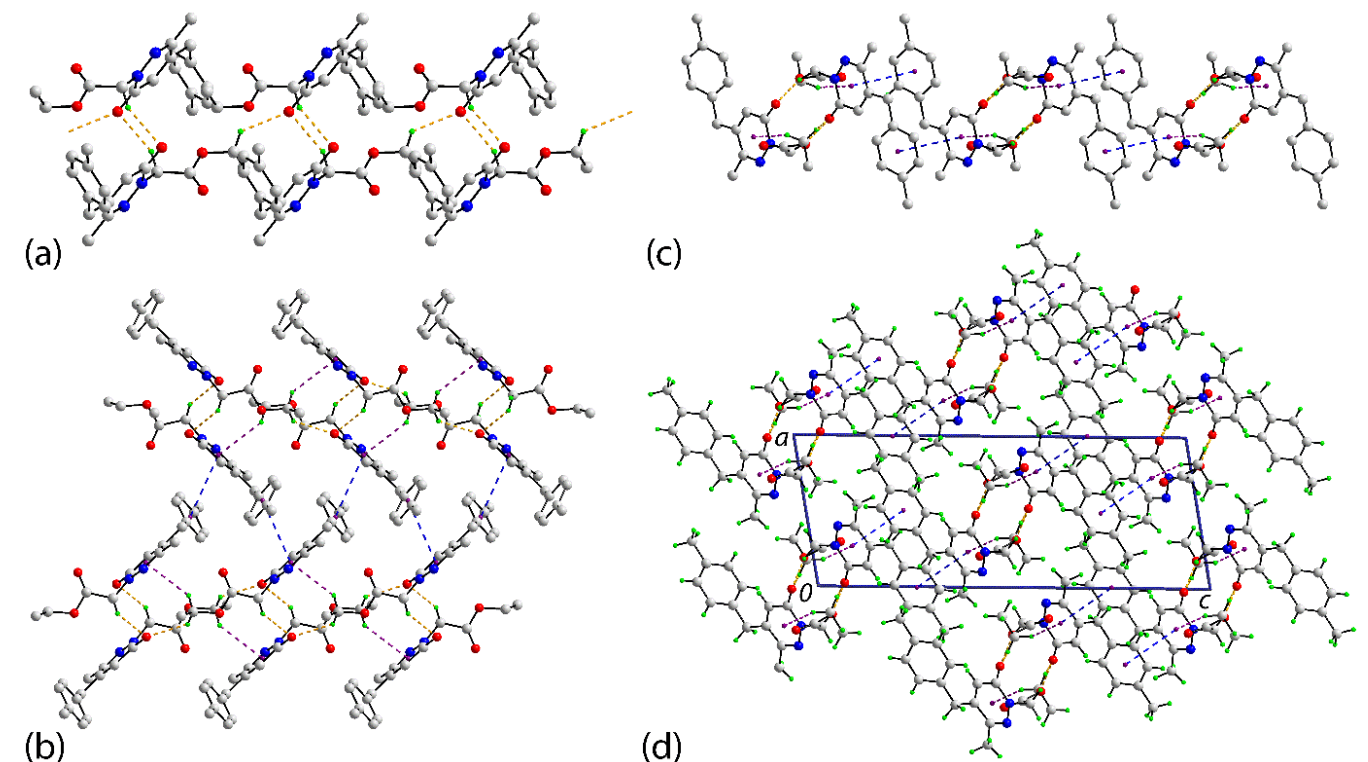

Fig. 2. Molecular packing in the crystal of 1 : (a) supramolecular chain sustained by $\mathrm{C}-\mathrm{H} \cdots \mathrm{O}$ contacts, shown as orange dashed lines, (b) supramolecular layer parallel to $\left(\begin{array}{lll}-1 & 0 & 1\end{array}\right)$ with $\mathrm{C}-$ $\mathrm{H}^{\cdots} \pi$ and $\pi^{\cdots} \pi$ interactions shown as purple and blue dashed lines, respectively, (c) a side-on 
view of the layer shown in (b) and (d) a view of the unit-cell contents in projection down the a-axis. In (a)-(c), non-participating hydrogen atoms are omitted for reasons of clarity. Intermolecular contacts: $\mathrm{C} 5-\mathrm{H} 5 \mathrm{~b} \cdots \mathrm{O} 1^{\mathrm{i}}: \mathrm{H} 5 \mathrm{~b} \cdots \mathrm{O} 1^{\mathrm{i}}=2.44 \AA, \mathrm{C} 5 \cdots \mathrm{O} 1^{\mathrm{i}}=3.3284(14) \AA$ and angle at $\mathrm{H} 5 \mathrm{~b}=150^{\circ} ; \mathrm{C} 7-\mathrm{H} 7 \mathrm{a} \cdots \mathrm{O} 1^{\mathrm{ii}}: \mathrm{H}^{2} \mathrm{a}^{\cdots} \mathrm{O} 1^{\mathrm{ii}}=2.45 \AA, \mathrm{C}^{\cdots} \cdots \mathrm{O} 1^{\mathrm{ii}}=3.1761(14) \AA$ and angle at $\mathrm{H} 7 \mathrm{a}=130^{\circ} ; \mathrm{C} 7-\mathrm{H} 7 \mathrm{~b} \cdots \mathrm{Cg}(\mathrm{N} 1, \mathrm{~N} 2, \mathrm{C} 1-\mathrm{C} 4)^{\mathrm{iii}}: \mathrm{H} 7 \mathrm{~b} \cdots \mathrm{Cg}(\mathrm{N} 1, \mathrm{~N} 2, \mathrm{C} 1-\mathrm{C} 4)^{\mathrm{iii}}=2.99 \AA$, $\mathrm{C} 7 \cdots \mathrm{Cg}(\mathrm{N} 1, \mathrm{~N} 2, \mathrm{C} 1-\mathrm{C} 4)^{\mathrm{iii}}=3.7776(13) \AA$ and angle at $\mathrm{H} 7 \mathrm{~b}=138^{\circ} ; \mathrm{Cg}(\mathrm{N} 1, \mathrm{~N} 2, \mathrm{C} 1-$ C4) ${ }^{\cdots} \mathrm{Cg}(\mathrm{C} 11-\mathrm{C} 16)^{\mathrm{iv}}=3.8258(6) \AA$, angle of inclination $=15.73(5)^{\circ}$. Symmetry operations: (i) 1-x, 1-y, 1-z; (ii) 1-x, -y, 1-z, (iii) x, -1+y, z; (iv) 1/2-x, -1/2+y, 1/2-z.

There is a clear distinction in the mode of association between molecules in each of $\mathbf{1}$ and phenyl analogue, 2. In the latter, the N-methylene group is pivotal in that both hydrogen atoms are engaged in the formation of a supramolecular tape via $\mathrm{C}-\mathrm{H} \cdots \mathrm{O}$ (ring carbonyl) and $\mathrm{C}-\mathrm{H}^{\cdots} \mathrm{N}$ (pyridazinyl) interactions as shown in Fig. 3. A three-dimensional architecture arises as the tapes are linked by a combination of methyl- and phenyl-C- $\mathrm{H} \cdots \mathrm{O}$ (ring carbonyl) and phenyl-C-H $\cdots \mathrm{O}($ ester carbonyl) interactions.

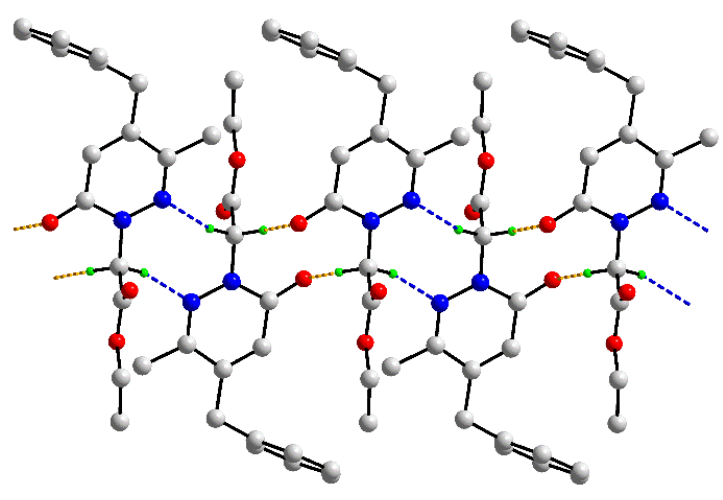

Fig. 3. A view of the supramolecular tape in the crystal of 2 sustained by $\mathrm{C}-\mathrm{H} \cdots \mathrm{O}$ (ring carbonyl) and $\mathrm{C}-\mathrm{H} \cdots \mathrm{N}$ (pyridazinyl) interactions shown as orange and blue dashed lines, respectively. 


\subsection{Theoretical molecular structures}

Molecule 1 was subjected to gas-phase geometry-optimisation and the optimised structure, hereafter 1g, was subsequently validated by a vibrational frequency analysis showing the result corresponds to a local minimum structure with zero imaginary frequency. Selected geometric data for the optimised structure are included in Table 2 for comparison with those determined for the experimental structure of 1 . An image showing the superimposition of the experimental and theoretical structures for $\mathbf{1}$ is shown in Supplementary Materials Fig. S5 which reveals that there has been a major adjustment in the optimised molecule in that the orientation of the ethylacetate residue is in close alignment with pseudo-mirror plane of the pyridazinyl ring. The conformational differences are quantified in the dihedral angles between the central pyridazinyl and 4-tolyl rings which compute to $81.92(3)^{\circ}$ for 1 and $87.9^{\circ}$ for 1g. The connection between the ring and ethylacetate group also presents significant differences as seen in the N2-N1-C5-C6, i.e. 120.40(10) and $91.9^{\circ}$ for $\mathbf{1}$ and $\mathbf{1 g}$, respectively, and N1-C5-C6-O3 torsion angles, i.e. 154.25(9) and 174.6º, respectively.

Geometry-optimisation was also performed on $\mathbf{2}$ to yield theoretical structure $\mathbf{2 g}$. The geometric parameters for $\mathbf{2 g}$ are included in Table 2 and the molecular conformations for $\mathbf{2}$ and $\mathbf{2 g}$ are also shown in Supplementary Materials Fig. S5, indicating no striking differences occurred upon geometry-optimisation. From the data in Table 2, it is clear no significant differences are apparent between the gas-phase molecules of $\mathbf{1 g}$ and $\mathbf{2 g}$ in terms of geometric parameters and molecular conformations. For $\mathbf{1 / 1}$, the RMSD for the molecules came to $0.388 \AA$ and for $\mathbf{2} / 2 \mathrm{~g}$ a smaller value was obtained, i.e. $0.224 \AA$.

\subsection{Prediction of molecular reactivity}


Several strategies were employed to study the molecular reactivity of $\mathbf{1}$, which include molecular electrostatic potential mapping (MEP), natural population analysis (NPA), condensed Fukui functions and dual descriptor calculation, natural bond orbital (NBO) analysis as well as frontier molecular orbital energy calculations. For meaningful evaluation of the computed data, a comparison was made with the closely related structural analogue, with the phenyl ring rather than 4-tolyl group, i.e. 2 [22].

The MEP mapping was performed on the optimised structures to ascertain the electropositive and electronegative sites in $\mathbf{1}$ and $\mathbf{2}$ with the aim of ascertaining any influence of the methyl substituent in $\mathbf{1}$ upon the overall electrostatic potential of the molecule compared with $\mathbf{2}$. As expected, an intense red region is observed for the oxo-O1 atom in each molecule, being reflective of electronegative oxygen centre, Fig. 4. Similar observations are noted for the other heteroatoms, namely the carboxylic acid-O2 and -O3 atoms as well as the hydrazineN1- and -N2 atoms, albeit with reduced intensity. In general, there are no significant deviations in the calculated electrostatic potentials in the pyridazinyl and ethylacetate fragments between $\mathbf{1}$ and 2. The electron-donating effect of the methyl substituent is barely observed on the phenyl ring: the electrostatic potential of the adjacent C14 is slightly reduced to -0.011 a.u. in 1 compared to -0.016 a.u. in unsubstituted 2 . Due to the weak inductive effect of the methyl group [55], $\mathbf{1}$ is found to possess slightly more negative electrostatic potential charge in $\mathrm{C} 11$ relative to that of $\mathbf{2}$. 

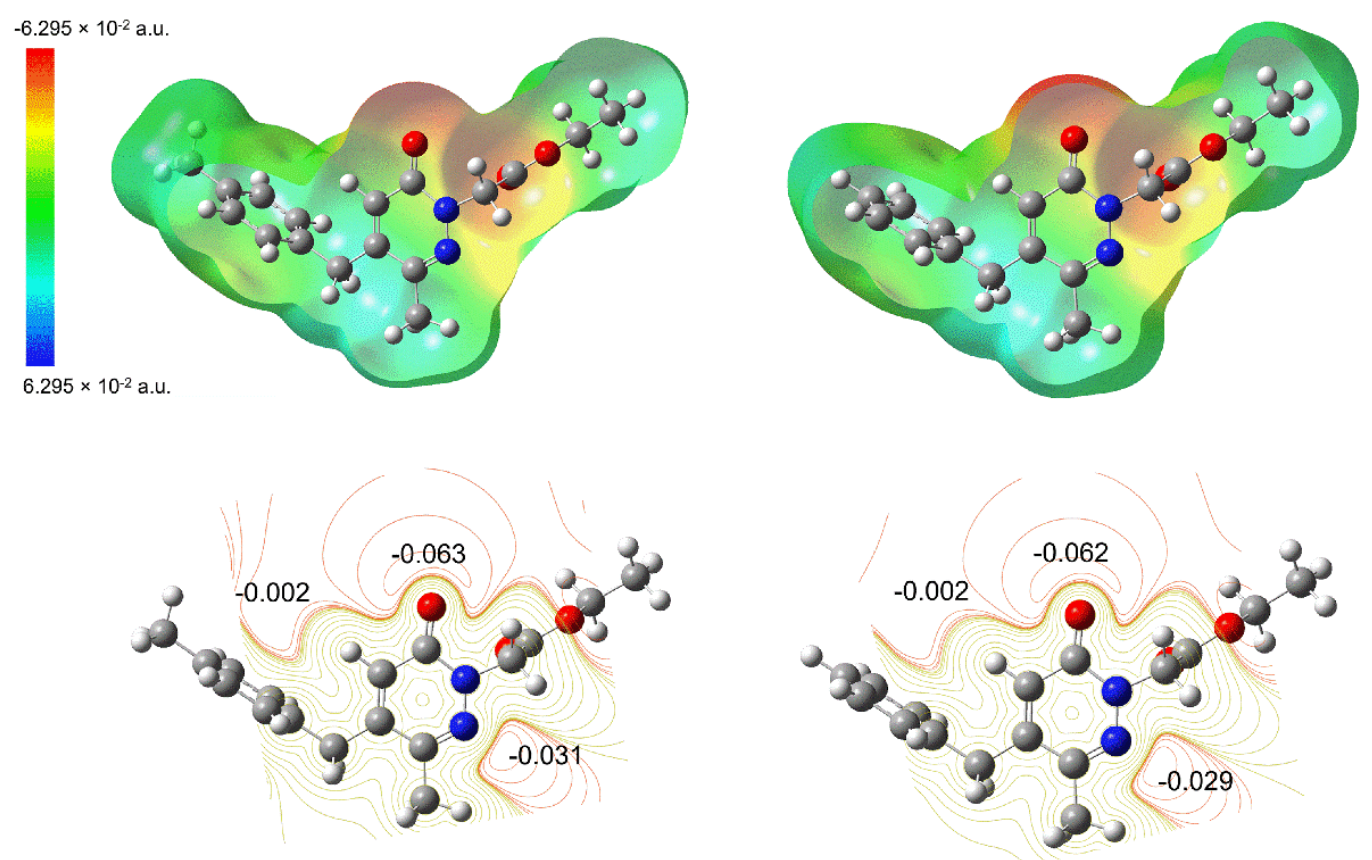

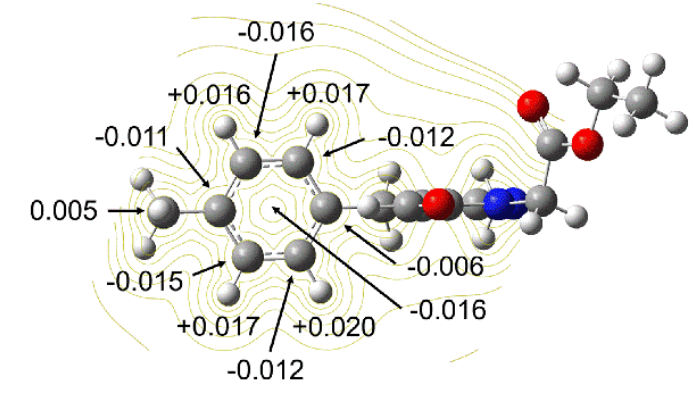

(a)

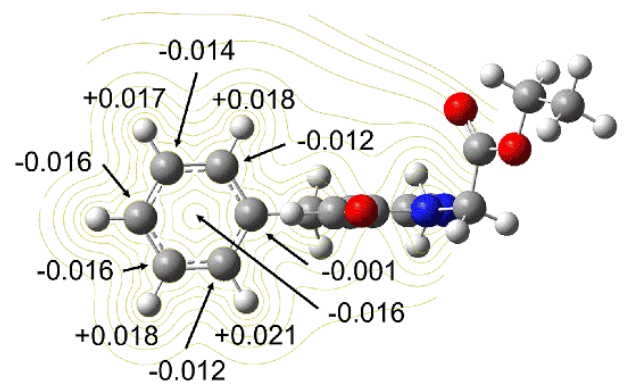

(b)

Fig. 4. The overall three-dimensional MEP maps (top) as well as the two-dimensional contour plot (iso-density value $=0.004$ a.u.) as projected on the central pyridazinyl (middle) and benzene rings (bottom) along with the total cumulative electrostatic charges for (a) $\mathbf{1}$ and (b) 2. The contour plots for the ethylacetate fragment were omitted owing similar total cumulative electrostatic charges between the two molecules.

The NPA analysis was performed to estimate the partial charges on atoms and to gain further insight into the electronic charge distribution within the molecules, in particular for the phenyl ring fragments so as to evaluate the effect of the methyl substituent in 2. NPA was chosen for the charge calculation as this approach has been reported to give reliable results while being 
less sensitive to the choice of basis set functions [56], despite it may not be suitable for ionic clusters [57]. The atomic charges for all non-hydrogen atoms are collated in Table 2. From the data, it can be observed that the central pyridazinyl ring and ethylacetate fragment in both 1 and $\mathbf{2}$ exhibit no significant charge deviations, with the $\mathrm{O} 1$ atom being the most basic atom among all. For the other heteroatoms, the electronegativity decreased in the order $\mathrm{O} 2>\mathrm{O} 3>$ N2 $>$ N1. More notable differences were evident for the substituted phenyl ring. Thus, the C14 atom exhibits relatively less negative charge (-0.019 vs -0.207 e) in 1 compared to $\mathbf{2}$, while the opposite trend, albeit less dramatic, is true for the C11 atom (-0.035 vs -0.023 e). Overall, the majority of phenyl carbons in $\mathbf{2}$ have reduced electronegativity compared to their counterparts in 1 with the net charge shift, [ $\left.\sum q\left(\mathrm{C}_{6} \mathrm{H}_{4}\right)_{2}-\sum q\left(\mathrm{C}_{6} \mathrm{H}_{5}\right)_{1}\right]$ [56], being -0.030 e indicating that the methyl substituent is withdrawing electron-density, consistent with expectation $[58,59]$.

To complement the NPA analysis, $\mathbf{1}$ and $\mathbf{2}$ were also subjected to condensed Fukui function calculation based on Parr and Yang's conceptual density theory (CDFT) [60-62] which are expressed in the following equations (4)-(6) [37]:

$$
\begin{aligned}
& \text { For nucleophilic attack: } \hat{f}_{k}^{+}=q_{k}(N+1)-q_{k}(N) \\
& \text { For electrophilic attack: } f_{k}=q_{k}(N)-q_{k}(N-1) \\
& \text { For radical reaction: } f_{k}^{0}=1 / 2\left[q_{k}(N+1)-q_{k}(N-1)\right]
\end{aligned}
$$

In the equations, $q_{\mathrm{k}}$ represents the atomic charges of $k^{\text {th }}$ atom in the neutral $(N)$, cationic $(N-$ 1) and anionic $(N+1)$ states in a frozen orbital approximation. According to the theory, the higher value of $f$ indicates a greater propensity for the reaction to occur at the activated site of the molecule [37]. Nevertheless, the interpretation of the data is not always straightforward, 
particularly for negative Fukui function values which can be associated with orbital relaxation effects [63]. In this context, the dual descriptor (equation 7) [38,39] offers an unambiguous description on the nucleophilic and electrophilic behaviour of the active sites within a molecule without being affected by relaxation effects [64].

$$
\Delta f(k)=f_{k}^{+}-f_{k}
$$

The nucleophilic and electrophilic behaviour is determined by the sign of the dual descriptor, whereby $\Delta f>0$ signifies a favourable site for nucleophilic attack while $\Delta f<0$ represents a favourable site for electrophilic attack [38,39]. In line with the MEP analysis, the O1, O2, $\mathrm{O} 3, \mathrm{~N} 1$ and $\mathrm{N} 2$ atoms in each of $\mathbf{1}$ and $\mathbf{2}$ exhibit negative dual descriptor values indicating that they are nucleophilic in nature and inclined for electrophilic attack (Table 3). Amongst these atoms, the carbonyl-O1 atoms has the lowest dual descriptor value suggesting that they have the greatest propensity for electrophilic attack. On the other hand, an influence due the methyl substituent upon the phenyl ring is noted, whereby the $\mathrm{C} 14$ atom in $\mathbf{1}$ exhibits a positive sign for the dual descriptor in contrast to the negative sign for $\mathbf{2}$. This signifies that the former has a greater probability for nucleophilic attack while the opposite is true for the latter. This observation is consistent with the MEP and NPA charges for the corresponding atoms which can be rationalised in terms of the inductive effect. As expected, the methyl substituent exerts little influence over the remaining part of the molecule as no apparent trends in the signs of the dual descriptor are evident.

\section{Table 3}

Comparison of NPA charge, condensed Fukui functions $\left(f^{*}\right.$ and $\left.f^{+}\right)$and dual descriptor $(\Delta f)$ for all non-hydrogen atoms in $\mathbf{1}$ and $\mathbf{2}$, all units are in electron, $|\mathrm{e}|{ }^{\mathrm{a}}$ 


\begin{tabular}{|c|c|c|c|c|c|c|c|c|}
\hline \multirow[t]{2}{*}{ Atom } & \multicolumn{4}{|c|}{1} & \multicolumn{4}{|c|}{2} \\
\hline & NPA & $f^{-}$ & $f^{+}$ & $\Delta f$ & NPA & $f^{-}$ & $f^{+}$ & $\Delta f$ \\
\hline $\mathrm{O} 1$ & -0.614 & -0.090 & -0.213 & -0.123 & -0.613 & -0.089 & -0.216 & -0.127 \\
\hline $\mathrm{O} 2$ & -0.577 & -0.012 & -0.020 & -0.008 & -0.573 & -0.011 & -0.026 & -0.015 \\
\hline $\mathrm{O} 3$ & -0.483 & -0.016 & -0.018 & -0.002 & -0.484 & -0.015 & -0.016 & -0.001 \\
\hline N1 & -0.189 & -0.065 & -0.100 & -0.035 & -0.188 & -0.067 & -0.114 & -0.047 \\
\hline N2 & -0.196 & -0.048 & -0.163 & -0.115 & -0.195 & -0.052 & -0.165 & -0.113 \\
\hline $\mathrm{C} 1$ & 0.159 & -0.031 & -0.096 & -0.065 & 0.158 & -0.031 & -0.114 & -0.083 \\
\hline $\mathrm{C} 2$ & 0.013 & -0.135 & -0.007 & 0.128 & 0.012 & -0.136 & -0.013 & 0.123 \\
\hline $\mathrm{C} 3$ & -0.242 & -0.191 & -0.064 & 0.127 & -0.242 & -0.193 & -0.082 & 0.111 \\
\hline $\mathrm{C} 4$ & 0.566 & 0.012 & 0.024 & 0.012 & 0.566 & 0.012 & 0.031 & 0.019 \\
\hline $\mathrm{C} 5$ & -0.317 & 0.007 & 0.012 & 0.005 & -0.316 & 0.009 & 0.012 & 0.003 \\
\hline C6 & 0.767 & -0.007 & 0.005 & 0.012 & 0.768 & -0.015 & 0.003 & 0.018 \\
\hline $\mathrm{C} 7$ & -0.077 & 0.001 & 0.003 & 0.002 & -0.070 & 0.000 & 0.003 & 0.003 \\
\hline C8 & -0.618 & 0.002 & 0.002 & 0.000 & -0.608 & 0.003 & 0.004 & 0.001 \\
\hline C9 & -0.620 & 0.014 & 0.020 & 0.006 & -0.620 & 0.015 & 0.024 & 0.009 \\
\hline $\mathrm{C} 10$ & -0.436 & 0.020 & 0.017 & -0.003 & -0.437 & 0.020 & 0.009 & -0.011 \\
\hline C11 & -0.035 & 0.046 & -0.053 & -0.099 & -0.023 & 0.041 & -0.068 & -0.109 \\
\hline C12 & -0.194 & -0.005 & -0.019 & -0.014 & -0.203 & -0.001 & -0.025 & -0.024 \\
\hline C13 & -0.196 & -0.018 & -0.045 & -0.027 & -0.195 & -0.019 & -0.052 & -0.033 \\
\hline $\mathrm{C} 14$ & -0.019 & -0.026 & -0.012 & 0.014 & -0.207 & -0.025 & -0.086 & -0.061 \\
\hline C15 & -0.197 & -0.016 & -0.031 & -0.015 & -0.196 & -0.018 & -0.035 & -0.017 \\
\hline $\mathrm{C} 16$ & -0.195 & -0.007 & -0.024 & -0.017 & -0.204 & -0.006 & -0.039 & -0.033 \\
\hline C17 & -0.610 & 0.009 & 0.017 & 0.008 & - & - & - & - \\
\hline
\end{tabular}


a The condensed Fukui function for the radical reaction term $\left(f^{\theta}\right)$ is omitted from the comparison.

\subsection{Natural bond orbital (NBO) analysis}

Apart from NPA charge analysis, values for the Wiberg bond index [65] were obtained through an NBO analysis in order to assess the electron population overlap between pairs of atoms. The results are collated in Table 4 and show that the Wiberg index is almost the same for comparable pairs of atoms in $\mathbf{1}$ and $\mathbf{2}$. The only notable exceptions are for the C13-C14 and $\mathrm{C} 14-\mathrm{C} 15$ bonds for which the indices are smaller in $\mathbf{1}$ when compared to $\mathbf{2}$, indicating that the methyl substituent withdraws some of the electron population from these bonds, again consistent with the previous findings from the analysis of the condensed Fukui functions and dual descriptors.

\section{Table 4}

A comparison of Wiberg bond orders for all non-hydrogen bonds in $\mathbf{1}$ and $\mathbf{2}$.

\begin{tabular}{lcc}
\hline Bond & \multicolumn{2}{c}{ Wiberg index } \\
\cline { 2 - 3 } & $\mathbf{1}$ & $\mathbf{2}$ \\
\hline O1-C4 & 1.800 & 1.791 \\
O2-C6 & 1.874 & 1.877 \\
O3-C6 & 0.944 & 0.945 \\
O3-C7 & 0.977 & 0.979 \\
N1-C4 & 0.936 & 0.942 \\
N1-N2 & 0.977 & 0.976 \\
N1-C5 & 0.981 & 0.981 \\
N2-C1 & 1.778 & 1.786
\end{tabular}




$\begin{array}{lll}\mathrm{C} 1-\mathrm{C} 2 & 0.965 & 0.968 \\ \mathrm{C} 1-\mathrm{C} 9 & 0.981 & 0.979 \\ \mathrm{C} 2-\mathrm{C} 3 & 1.789 & 1.794 \\ \mathrm{C} 2-\mathrm{C} 10 & 0.972 & 0.971 \\ \mathrm{C} 3-\mathrm{C} 4 & 0.959 & 0.959 \\ \mathrm{C} 5-\mathrm{C} 6 & 0.943 & 0.944 \\ \mathrm{C} 7-\mathrm{C} 8 & 0.990 & 0.991 \\ \mathrm{C} 10-\mathrm{C} 11 & 0.980 & 0.979 \\ \mathrm{C} 11-\mathrm{C} 12 & 1.629 & 1.632 \\ \mathrm{C} 12-\mathrm{C} 13 & 0.984 & 0.983 \\ \mathrm{C} 13-\mathrm{C} 14 & 1.628 & 1.653 \\ \mathrm{C} 14-\mathrm{C} 15 & 0.977 & 0.985 \\ \mathrm{C} 15-\mathrm{C} 16 & 1.655 & 1.651 \\ \mathrm{C} 16-\mathrm{C} 11 & 0.977 & 0.980 \\ \mathrm{C} 14-\mathrm{C} 17 & 0.986 & -\end{array}$

The interpretation of hyper-conjugative or delocalisation of electron density between occupied Lewis-type NBO orbitals (i.e. donors) and unoccupied non-Lewis NBO orbitals (i.e. acceptors) was also achieved through an NBO analysis by estimating the stabilisation energy $E^{2}$ using the second order perturbation theory, in which a larger value of $E^{2}$ represents a stronger electron donor-acceptor interaction [66]. Selected donor-acceptor interactions with significant stabilisation energy $\left(E^{2}>10 \mathrm{kcal} / \mathrm{mol}\right)$ are collated in Table 5. From these data, a clear differentiation is observed in the stabilisation energies of the phenyl rings in $\mathbf{1}$ and $\mathbf{2}$, where the former exhibits slightly greater values of $E^{2}(\sim 1$ to $2 \mathrm{kcal} / \mathrm{mol})$. This result indicates that is an increase of electron-delocalisation within the phenyl ring which can be 
traced to the influence of the methyl substituent in 1. Overall, there is little deviation in $E^{2}$ observed for the pyridazinyl rings and ethylacetate fragments in $\mathbf{1}$ and $\mathbf{2}$. Among all the donor-acceptor interactions, the N1 LP (1) $\rightarrow \pi^{*}(\mathrm{O} 1-\mathrm{C} 4)$ and LP (2) O3 $\rightarrow \pi^{*}(\mathrm{O} 2-\mathrm{C} 6)$ transitions exhibit the greatest stabilisation energies of $\sim 58$ and $\sim 51 \mathrm{kcal} / \mathrm{mol}$, respectively.

\section{Table 5}

A comparison of the second order perturbation energies, $E^{2}$ for selected bonding $\left(E^{2}>10\right.$ $\mathrm{kcal} / \mathrm{mol}$ ) between $\mathbf{1}$ and $\mathbf{2}{ }^{\mathrm{a}}$

\begin{tabular}{|c|c|c|c|c|c|}
\hline \multirow[t]{2}{*}{ Donor } & \multirow[t]{2}{*}{ Type } & \multirow[t]{2}{*}{ Acceptor } & \multirow[t]{2}{*}{ Type } & \multicolumn{2}{|c|}{$\begin{array}{c}\text { Stabilisation Energy, } E^{2} \\
(\mathrm{kcal} / \mathrm{mol})\end{array}$} \\
\hline & & & & 1 & 2 \\
\hline N1 & LP (1) & $\mathrm{O} 1-\mathrm{C} 4$ & $\mathrm{BD}^{*}(2)$ & 57.62 & 57.94 \\
\hline $\mathrm{O} 3$ & LP (2) & $\mathrm{O} 2-\mathrm{C} 6$ & $\mathrm{BD}^{*}(2)$ & 51.25 & 51.78 \\
\hline N1 & LP (1) & $\mathrm{N} 2-\mathrm{C} 1$ & $\mathrm{BD}^{*}(2)$ & 33.49 & 33.17 \\
\hline $\mathrm{O} 2$ & LP (2) & $\mathrm{O} 3-\mathrm{C} 6$ & $\mathrm{BD}^{*}(1)$ & 33.47 & 33.05 \\
\hline $\mathrm{O} 1$ & LP (2) & $\mathrm{N} 1-\mathrm{C} 4$ & $\mathrm{BD} *(1)$ & 31.27 & 29.32 \\
\hline $\mathrm{O} 2$ & LP (2) & $\mathrm{C} 5-\mathrm{C} 6$ & $\mathrm{BD}^{*}(1)$ & 23.78 & 23.93 \\
\hline $\mathrm{C} 2-\mathrm{C} 3$ & $\mathrm{BD}(2)$ & $\mathrm{O} 1-\mathrm{C} 4$ & $\mathrm{BD} *(2)$ & 22.68 & 22.38 \\
\hline $\mathrm{C} 15-\mathrm{C} 16$ & $\mathrm{BD}(2)$ & $\mathrm{C} 11-\mathrm{C} 12$ & $\mathrm{BD}^{*}(2)$ & 22.16 & 21.42 \\
\hline $\mathrm{C} 13-\mathrm{C} 14$ & $\mathrm{BD}(2)$ & $\mathrm{C} 15-\mathrm{C} 16$ & $\mathrm{BD} *(2)$ & 21.70 & 20.89 \\
\hline $\mathrm{C} 11-\mathrm{C} 12$ & $\mathrm{BD}(2)$ & $\mathrm{C} 13-\mathrm{C} 14$ & $\mathrm{BD}^{*}(2)$ & 22.45 & 20.17 \\
\hline $\mathrm{C} 15-\mathrm{C} 16$ & $\mathrm{BD}(2)$ & $\mathrm{C} 13-\mathrm{C} 14$ & $\mathrm{BD}^{*}(2)$ & 21.18 & 19.50 \\
\hline $\mathrm{C} 11-\mathrm{C} 12$ & $\mathrm{BD}(2)$ & $\mathrm{C} 15-\mathrm{C} 16$ & $\mathrm{BD} *(2)$ & 21.65 & 19.37 \\
\hline $\mathrm{C} 13-\mathrm{C} 14$ & $\mathrm{BD}(2)$ & $\mathrm{C} 11-\mathrm{C} 12$ & $\mathrm{BD} *(2)$ & 20.36 & 19.15 \\
\hline $\mathrm{O} 2$ & LP (1) & C6 & $\mathrm{RY}^{*}(1)$ & 18.71 & 18.27 \\
\hline
\end{tabular}




$\begin{array}{llllll}\text { O1 } & \text { LP (2) } & \text { C3-C4 } & \text { BD*(1) } & 18.51 & 18.30 \\ \text { C2-C3 } & \text { BD (2) } & \text { N2-C1 } & \text { BD*(2) } & 18.37 & 18.87 \\ \text { O1 } & \text { LP (1) } & \text { C4 } & \text { RY*(1) } & 16.10 & 15.70 \\ \text { N2 } & \text { LP (1) } & \text { C1-C2 } & \text { BD*(1) } & 12.02 & 11.61 \\ \text { N2 } & \text { LP (1) } & \text { N1-C4 } & \text { BD* (1) } & 11.98 & 11.02 \\ \text { N2-C1 } & \text { BD (2) } & \text { C2-C3 } & \text { BD* (2) } & 11.01 & 10.94\end{array}$

a LP denotes a lone-pair; BD a two-centre bond; BD* a two-centre anti-bonding; RY* a onecentre Rydberg

\subsection{Frontier molecular orbital analysis}

A frontier molecular orbital analysis was performed to complement the condensed Fukui function and dual descriptor calculations in predicting the chemical reactivity of $\mathbf{1}$ and $\mathbf{2}$. The plots of the Highest Occupied Molecular Orbital (HOMO) and Lowest Unoccupied Molecular Orbital (LUMO) of 1 and 2 from the ground state $\left(S_{0}\right)$ to the first excitation state $\left(S_{1}\right)$ are presented in Supplementary Materials Fig. S6. From the mapping, it can be observed that the HOMO electrons are mainly delocalised on the carbonyl-O1 atom while the LUMO electrons are delocalised over the $\mathrm{N} 2-\mathrm{C} 1$ atoms in the pyridazinyl ring with the energy gap being $0.2405 \mathrm{eV}$ for each of $\mathbf{1}$ and $\mathbf{2}$. Hence, it can be concluded that the methyl group in $\mathbf{1}$ has little effect upon the overall reactivity of the molecule.

\subsection{Theoretical studies for intermolecular interactions}

The intermolecular contacts identified for the crystal of $\mathbf{1}$ were studied both qualitatively and quantitatively to better understand the nature of the interactions that contribute to the packing pattern. Several approaches such as Hirshfeld surface analysis, non-covalent interaction plots, interaction energy calculations, energy framework simulation as well as crystal lattice energy 
calculations were employed for the study. A complementary analysis on $\mathbf{2}$ was used for comparison whenever relevant.

\subsection{Hirshfeld surface analysis}

Several close contacts were identified through the Hirshfeld surface analysis as revealed by the presence of red spots of varying intensity on the surface maps shown in Fig. 5, being indicative of contact distances shorter than the sum of van der Waals radii [42]. With the absence of conventional hydrogen bonds, the most intense red spots are observed for the

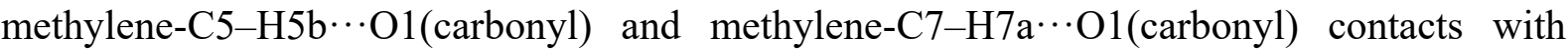
corresponding $d_{\text {norm }}$ contact distances of 2.36 and $2.39 \AA$, respectively, which are about 0.25 and $0.22 \AA$ shorter than the $\mathrm{H} \cdots \mathrm{O}$ van der Waals radii of $2.61 \AA$ (adjusted to neutron values), Table 6. Other noticeable contacts with relatively less intensity, which range from diminutive red to white spots arise due to $\mathrm{C} 1 \cdots \mathrm{C} 13$, methyl-C9-H9c $\cdots \mathrm{O} 2$ (carbonyl) as well as methylene-C5-H5a $\cdots \mathrm{N} 2$ (pyridazinyl) contacts with the $\mathrm{d}_{\text {norm }}$ distances being 3.37, 2.59 and

2.64 A, respectively, which are marginally shorter than or equivalent to their corresponding van der Waals radii. The aforementioned methylene-C5-H5a $\cdots \mathrm{N} 2$ (pyridazinyl) contacts appear to be the shortest atom-to-atom contacts between the layers that stack along the c-axis direction. 

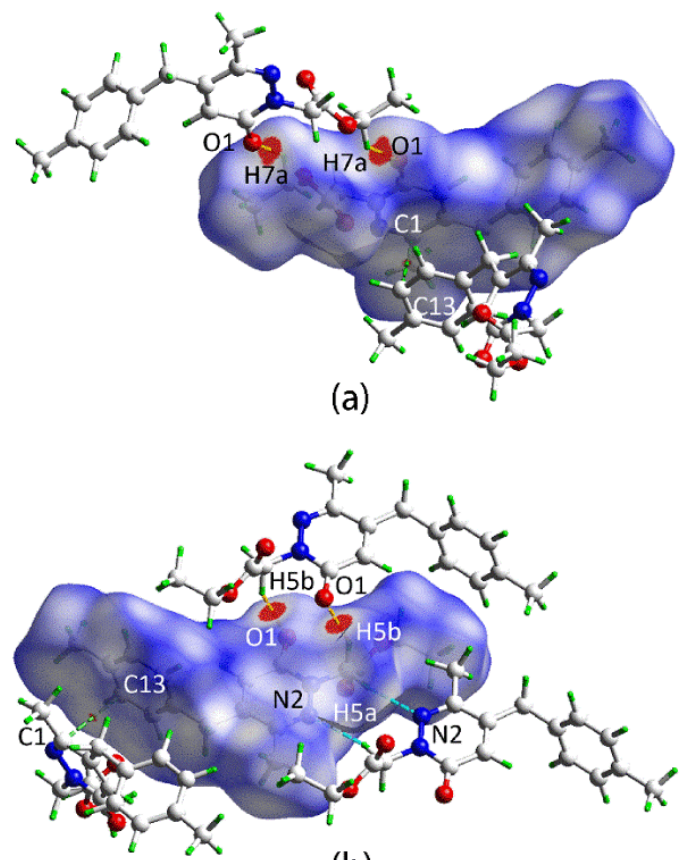

(b)

Fig. 5. Perspective views of the $d_{\text {norm }}$ map for $\mathbf{1}$, showing relevant short contacts indicated by the red spots on the Hirshfeld surface with varying intensities within the range of -0.0081 to 1.0105 arbitrary units highlighting: (a) $\mathrm{H} 7 \mathrm{a} \cdots \mathrm{O} 1$ and $\mathrm{C} 1 \cdots \mathrm{C} 13$ and (b) $\mathrm{H} 5 \mathrm{~b} \cdots \mathrm{O} 1, \mathrm{H} 5 \mathrm{a} \cdots \mathrm{N} 2$ and $\mathrm{C} 1 \cdots \mathrm{C} 13$.

Table 6

A summary of the $d_{\text {norm }}$ contact distances (adjusted to neutron values) for interactions present in $\mathbf{1}$, as computed through a Hirshfeld Surface analysis. ${ }^{\text {a }}$

\begin{tabular}{lllll}
\hline Contact & Distance $(\AA)$ & $\sum \mathrm{vdW}(\AA)$ & $\Delta\left|d_{\text {norm }}-\sum \mathrm{vdW}\right|$ & Symmetry Operation
\end{tabular}

( $)$

\begin{tabular}{lllll}
\hline $\mathrm{H} 5 \mathrm{~b} \cdots \mathrm{O} 1$ & 2.36 & 2.61 & 0.25 & $1-\mathrm{x}, 1-\mathrm{y}, 1-\mathrm{z}$ \\
$\mathrm{H} 7 \mathrm{a} \cdots \mathrm{O} 1$ & 2.39 & 2.61 & 0.22 & $1-\mathrm{x},-\mathrm{y}, 1-\mathrm{z}$ \\
$\mathrm{C} 1 \cdots \mathrm{C} 13$ & 3.37 & 3.40 & 0.03 & $1 / 2-\mathrm{x},-1 / 2+\mathrm{y}, 1 / 2-\mathrm{z}$ \\
$\mathrm{H} 9 \mathrm{c} \cdots \mathrm{O} 2$ & 2.59 & 2.61 & 0.02 & $\mathrm{x}, 1+\mathrm{y}, \mathrm{z}$ \\
$\mathrm{H} 5 \mathrm{a} \cdots \mathrm{N} 2$ & 2.64 & 2.64 & 0.00 & $-\mathrm{x}, 1-\mathrm{y}, 1-\mathrm{z}$
\end{tabular}


$\begin{array}{lllll}\mathrm{H} 10 \mathrm{a} \cdots \mathrm{H} 12 & 2.18 & 2.18 & 0.00 & 1 / 2-\mathrm{x}, 1 / 2+\mathrm{y}, 1 / 2-\mathrm{Z}\end{array}$

a $\sum \mathrm{vdW}=$ sum of the respective van der Waals

Having identified the interaction between the $\mathrm{C} 1$ and $\mathrm{C} 13$ atoms, Table 6 and Fig. 5, this close contact was further established through the plotting of the Hirshfeld surface over the curvedness which reveals that the presence of this interaction is supported by shape complementarity between the pyridazinyl and phenyl rings, Fig. 6a. A similar finding is also noted for the additional $\pi$-contact involving the pyridazinyl ring and methylene- $\mathrm{C} 7-\mathrm{H} 7 \mathrm{~b}$ atom, as evidenced through the complementary concave and convex shapes between the centre of the ring and the $\mathrm{H} 7 \mathrm{~b}$ atom, Fig. $6 \mathrm{~b}$.
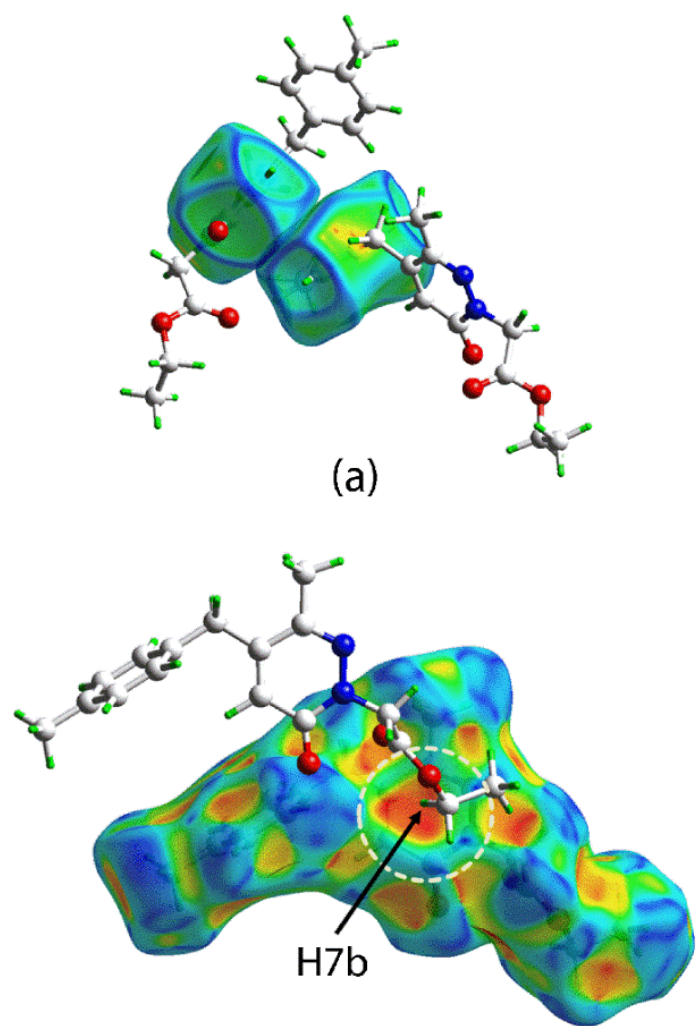

(b)

Fig. 6. (a) The Hirshfeld surface mapped with curvedness (property range: -4.0 to +0.4 arbitrary units) for $\pi(\mathrm{N} 1-\mathrm{C} 4) \cdots \pi(\mathrm{C} 11-\mathrm{C} 16)$ and (b) Hirshfeld surface mapped with the shape index property (range: -1.0 to +1.0 arbitrary units) for the pyridazinyl ring (highlighted by the circle) interacting with the methylene-H7b atom. 
The quantification of the corresponding close contacts was achieved through an analysis of the full and delineated two-dimensional fingerprint plots, Fig. 7, which shows that the distribution of contacts on the Hirshfeld surface of 1 is dominated by $\mathrm{H} \cdots \mathrm{H}(55.7 \%)$ contacts followed by $\mathrm{H}^{\cdots} \mathrm{O} / \mathrm{O} \cdots \mathrm{H}(21.5 \%), \mathrm{H}^{\cdots} \mathrm{C} / \mathrm{C} \cdots \mathrm{H}(12.9 \%)$ and $\mathrm{H} \cdots \mathrm{N} / \mathrm{N} \cdots \mathrm{H}(6.4 \%)$ contacts. The corresponding minimum $\mathrm{d}_{\mathrm{i}}+\mathrm{de}_{\mathrm{e}}$ peaks for $\mathrm{H} \cdots \mathrm{H}, \mathrm{H} \cdots \mathrm{O} / \mathrm{O} \cdots \mathrm{H}, \mathrm{H} \cdots \mathrm{C} / \mathrm{C} \cdots \mathrm{H}$ and $\mathrm{H} \cdots \mathrm{N} / \mathrm{N} \cdots \mathrm{H}$ are attributed to the $\mathrm{H} 10 \mathrm{a} \cdots \mathrm{H} 12\left(\mathrm{~d}_{\mathrm{i}}+\mathrm{d}_{\mathrm{e}} \sim 2.16 \AA\right), \mathrm{O} 1 \cdots \mathrm{H} 5 \mathrm{~b}\left(\mathrm{~d}_{\mathrm{i}}+\mathrm{d}_{\mathrm{e}} \sim 2.36 \AA\right)$, C4 $\cdots$ H5b $\left(d_{i}+d_{e} \sim 2.86 \AA\right)$ and $N 2 \cdots H 5 a\left(d_{i}+d_{e} \sim 2.64 \AA\right)$ contacts. Overall, the heterogeneous contacts are slightly inclined towards (internal)-X $\cdots \mathrm{H}-($ external), Fig. 7, reflecting the lack of molecular symmetry in $\mathbf{1}$ coupled with the observation that hydrogen accepting atoms are dominant over hydrogen donor atoms. A comparison of the contact distribution between 1 and 2, Table 7, shows that generally there is not much deviation between the patterns of surface contacts, with the latter exhibiting a slightly greater distribution in the heterogeneous contacts compared to the former.
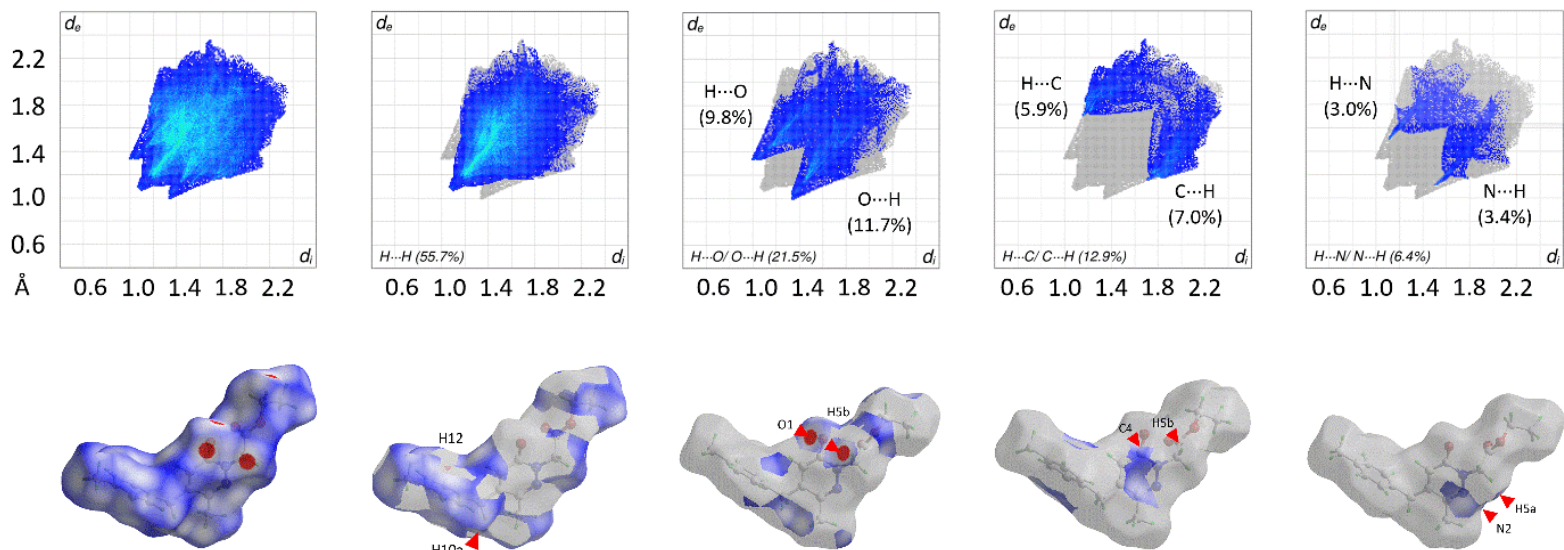

(a)
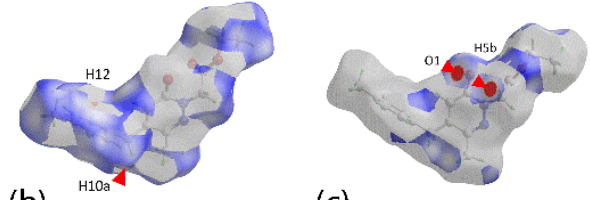

(c)

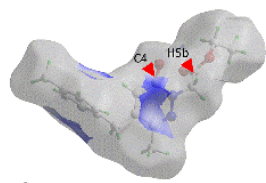

(d)

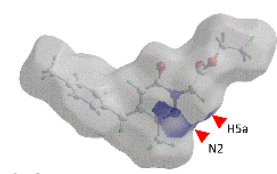

(e)

Fig. 7. (a) The overall two-dimensional fingerprint plot for $\mathbf{1}$ as well as those delineated into (b) $\mathrm{H} \cdots \mathrm{H}$, (c) $\mathrm{H} \cdots \mathrm{O} / \mathrm{O} \cdots \mathrm{H}$, (d) $\mathrm{H} \cdots \mathrm{C} / \mathrm{C} \cdots \mathrm{H}$ and (e) $\mathrm{H} \cdots \mathrm{N} / \mathrm{N} \cdots \mathrm{H}$ contacts, with the prominent tips of the fingerprint plot corresponding to the relevant contacts highlighted on the Hirshfeld surface by red cursors. 


\section{Table 7}

A comparison of the percentage distributions of close Hirshfeld surface contacts in $\mathbf{1}$ and $\mathbf{2}$.

\begin{tabular}{lcc}
\hline Contact & \multicolumn{2}{c}{ \% distribution of close contact } \\
& $\mathbf{1}$ & $\mathbf{2}$ \\
\hline $\mathrm{H} \cdots \mathrm{H}$ & 55.7 & 52.2 \\
$\mathrm{H} \cdots \mathrm{O} / \mathrm{O} \cdots \mathrm{H}$ & 21.5 & 23.3 \\
$\mathrm{H} \cdots \mathrm{C} / \mathrm{C} \cdots \mathrm{H}$ & 12.9 & 14.7 \\
$\mathrm{H} \cdots \mathrm{N} / \mathrm{N} \cdots \mathrm{H}$ & 6.4 & 6.6 \\
Other & 3.5 & 3.2
\end{tabular}

\subsection{Interaction energy calculations}

The strength of all close contacts in the crystal of $\mathbf{1}$ was assessed quantitatively by the calculation of the corresponding interaction energies. As shown in Table 8 , the $\pi \cdots \pi$ interaction involving the pyridazinyl and phenyl ring is found to have the greatest interaction energy among all pairwise interactions with the $E_{\text {total }}$ being $-10.7 \mathrm{kcal} / \mathrm{mol}$, an energy within the range -1.0 to $-15.1 \mathrm{kcal} / \mathrm{mol}$ normally found for $\pi \cdots \pi$ interactions [64]. The pairwise $\mathrm{C} 7-$ $\mathrm{H} 7 \mathrm{a} \cdots \mathrm{O} 1$ and $\mathrm{C} 5-\mathrm{H} 5 \mathrm{~b} \cdots \mathrm{O} 1$ interactions constitute next strongest interactions with $E_{\text {total }}$ being -9.5 and $-9.0 \mathrm{kcal} / \mathrm{mol}$, respectively. As expected, the inter-layer $\mathrm{C} 5-\mathrm{H} 5 \mathrm{a} \cdots \mathrm{N} 2$ interaction displays an $E_{\text {total }}$ of $-6.5 \mathrm{kcal} / \mathrm{mol}$ which is less compared with the $\mathrm{C}-\mathrm{H} \cdots \mathrm{O}$ counterpart due to the relatively reduced electrostatic potential in the nitrogen atom, compared to oxygen, as shown from the MEP mapping.

The phenyl analogue 2 , exhibits comparable interactions which are equivalent to $\pi(\mathrm{N} 1, \mathrm{~N} 2, \mathrm{C} 1-$ $\mathrm{C} 4) \cdots \pi(\mathrm{C} 11-\mathrm{C} 16), \mathrm{C} 5-\mathrm{H} 5 \mathrm{~b} \cdots \mathrm{O} 1, \mathrm{C} 7-\mathrm{H} 7 \mathrm{~b} \cdots \pi(\mathrm{N} 1, \mathrm{~N} 2, \mathrm{C} 1-\mathrm{C} 4)$ and $\mathrm{C} 5-\mathrm{H} 5 \mathrm{a} \cdots \mathrm{N} 2$ interactions 
in 1, with the corresponding $E_{\text {total }}$ values being $-9.3,-5.9,-2.7$ and $-7.1 \mathrm{kcal} / \mathrm{mol}$, respectively, Table 8 . Interestingly, it can be observed that the $\pi \cdots \pi$ interaction in $\mathbf{2}$ is slightly weaker in energy than that in $\mathbf{1}$ which may be related to the increased electron delocalisation in the methylated-phenyl ring in $\mathbf{1}$ as evidenced through the NBO and frontier molecular orbital analyses. As a result, 1 exhibits slightly stronger $\pi \cdots \pi$ interaction than 2 by $\sim 1.4 \mathrm{kcal} / \mathrm{mol}$ with a concomitant decrease in the respective centroid-to-centroid distances from 3.9573(7) $\AA$ in 2 to $3.8258(6) \AA$ in $\mathbf{1}$.

Table 8

Interaction energies $(\mathrm{kcal} / \mathrm{mol})$ for close contacts present in $\mathbf{1}$ and $\mathbf{2}$.

\begin{tabular}{|c|c|c|c|c|c|c|}
\hline Close contact & $E_{\text {ele }}$ & $E_{\mathrm{pol}}$ & $E_{\text {dis }}$ & $E_{\text {rep }}$ & $E_{\text {total }}$ & $\begin{array}{l}\text { Symmetry } \\
\text { operation }\end{array}$ \\
\hline \multicolumn{7}{|l|}{1} \\
\hline$\pi(\mathrm{N} 1, \mathrm{~N} 2, \mathrm{C} 1-$ & -3.4 & -1.0 & -11.8 & 5.5 & -10.7 & $1 / 2-x,-1 / 2+y, 1 / 2-z$ \\
\hline \multicolumn{7}{|c|}{$\mathrm{C} 4) \cdots \pi(\mathrm{C} 11-\mathrm{C} 16)+$} \\
\hline \multicolumn{7}{|l|}{$\mathrm{H} 10 \mathrm{a} \cdots \mathrm{H} 12$} \\
\hline$\{\mathrm{C} 7-\mathrm{H} 7 \mathrm{a} \cdots \mathrm{O} 1\}_{2}$ & -6.1 & -1.9 & -5.9 & 4.3 & -9.5 & $1-\mathrm{x},-\mathrm{y}, 1-\mathrm{z}$ \\
\hline$\{\mathrm{C} 5-\mathrm{H} 5 \mathrm{~b} \cdots \mathrm{O} 1\}_{2}$ & -4.0 & -1.3 & -8.5 & 4.7 & -9.0 & $1-x, 1-y, 1-z$ \\
\hline $\mathrm{C} 9-\mathrm{H} 9 \mathrm{c} \cdots \mathrm{O} 2+$ & -3.4 & -0.8 & -6.6 & 2.7 & -8.1 & $\mathrm{x}, 1+\mathrm{y}, \mathrm{z}$ \\
\hline \multicolumn{7}{|l|}{ C7- } \\
\hline \multicolumn{7}{|c|}{$\mathrm{H} 7 \mathrm{~b} \cdots \pi(\mathrm{N} 1, \mathrm{~N} 2, \mathrm{C} 1-\mathrm{C} 4)$} \\
\hline$\{\mathrm{C} 5-\mathrm{H} 5 \mathrm{a} \cdots \mathrm{N} 2\}_{2}$ & -3.5 & -0.3 & -6.7 & 4.1 & -6.5 & $-x, 1-y, 1-z$ \\
\hline 2 & & & & & & \\
\hline
\end{tabular}




\begin{tabular}{lllllll}
\hline$\pi(\mathrm{N} 1 / \mathrm{C} 4) \cdots \pi(\mathrm{C} 11-$ & -3.3 & -1.0 & -9.9 & 4.9 & -9.3 & $1 \frac{112-\mathrm{x}, 1 / 2+\mathrm{y}, 1 / 2-\mathrm{z}}{}$ \\
$\mathrm{C} 16)$ & & & & & & \\
$\{\mathrm{C} 5-\mathrm{H} 5 \mathrm{~b} \cdots \mathrm{O} 1\}_{2}$ & -2.8 & -0.7 & -4.3 & 2.0 & -5.9 & $1-\mathrm{x}, 1-\mathrm{y}, 1-\mathrm{z}$ \\
$\mathrm{C} 7-$ & 0.3 & -0.4 & -3.9 & 1.3 & -2.7 & $\mathrm{x}, 1+\mathrm{y}, \mathrm{z}$ \\
$\mathrm{H} 7 \mathrm{~b} \cdots \pi(\mathrm{N} 1, \mathrm{~N} 2, \mathrm{C} 1-\mathrm{C} 4)$ & & & & & & \\
$\{\mathrm{C} 5-\mathrm{H} 5 \mathrm{a} \cdots \mathrm{N} 2\}_{2}$ & -5.0 & -0.5 & -7.6 & 6.1 & -7.1 & $2-\mathrm{x}, 1-\mathrm{y}, 1-\mathrm{z}$ \\
\hline
\end{tabular}

\subsection{Non-covalent interaction (NCI) plots}

The NCI plot calculations were performed to complement the quantitative energy calculations. The results demonstrate the $\pi(\mathrm{N} 1, \mathrm{~N} 2, \mathrm{C} 1-\mathrm{C} 4) \cdots \pi(\mathrm{C} 11-\mathrm{C} 16)$ interaction manifests as a relatively high-density, localised domain between the $\pi$-rings that further extends to nearby atomic clusters, Fig. 8 a. It could be for this reason that the $\pi \cdots \pi$ contact exhibits a relatively high $E_{\text {total }}$ compared to the rest of the contacts in the molecule. Similar observations are found for $\mathrm{C} 7-\mathrm{H} 7 \mathrm{a} \cdots \mathrm{O} 1$ (Fig. 8b) and C5-H5b $\cdots \mathrm{O} 1$ (Fig. 8c) for which an extended domain is noted on the neighbouring atoms despite the relatively smaller sizes of the domains as compared to that for the $\pi \cdots \pi$ interaction. The NCI plots for the C9-H9c $\cdots \mathrm{O} 2+$ $\mathrm{C} 7-\mathrm{H} 7 \mathrm{~b} \cdots \pi(\mathrm{N} 1, \mathrm{~N} 2, \mathrm{C} 1-\mathrm{C} 4)$ and inter-layer $\mathrm{C} 5-\mathrm{H} 5 \mathrm{a} \cdots \mathrm{N} 2$ interactions, shown in Fig. $8 \mathrm{~d}$ and 8e, respectively, mainly comprise small domains and thereby contribute relatively smaller $E_{\text {total }}$ values. Overall, all intermolecular interactions present in $\mathbf{1}$ are considered weak but attractive in nature with the reduced density being in the range of $-0.05<\operatorname{sign}\left(\lambda_{2}\right) \rho<0.05$ a.u. as shown in the corresponding two-dimensional reduced density gradient versus the density plots. The intramolecular $\mathrm{H} 7 \mathrm{~b} \cdots \mathrm{O} 2$ contact is the only interaction that shows a strong attractive nature with $\operatorname{sign}\left(\lambda_{2}\right) \rho<-0.25$ a.u. 

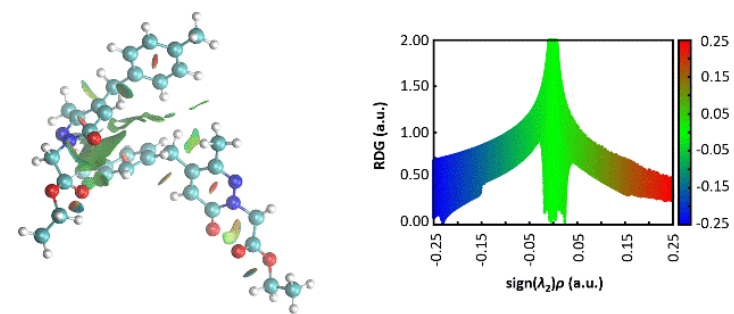

(a)

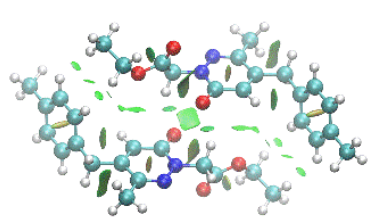

(c)
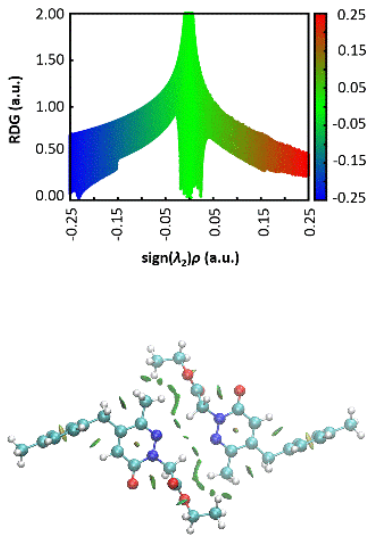

(e)

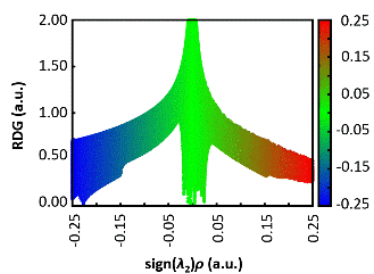

(b)

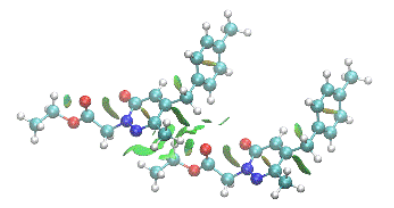

(d)
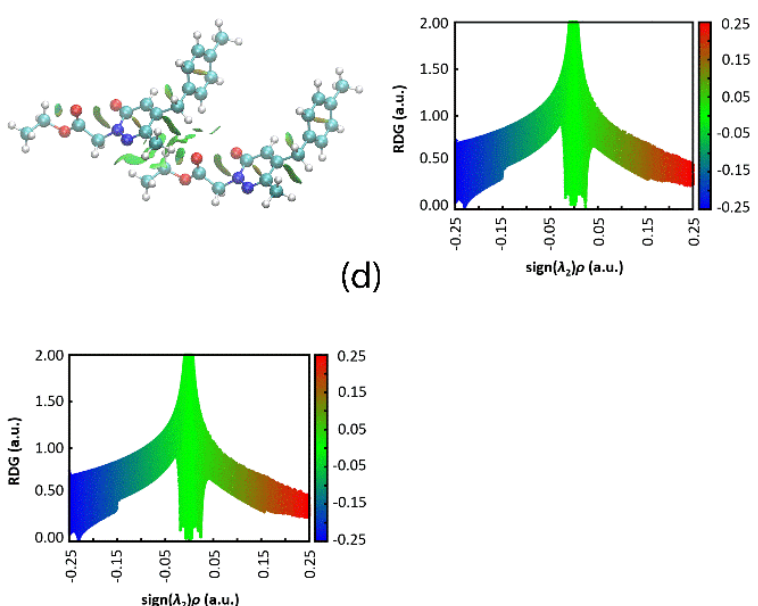

Fig. 8. The non-covalent interaction plots and corresponding RDG versus $\operatorname{sign}\left(\lambda_{2}\right) \rho$ plots for (a) $\pi(\mathrm{N} 1, \mathrm{~N} 2, \mathrm{C} 1-\mathrm{C} 4) \cdots \pi(\mathrm{C} 11 / \mathrm{C} 16)$, (b) $\mathrm{C} 7-\mathrm{H} 7 \mathrm{a} \cdots \mathrm{O} 1$, (c) $\mathrm{C} 5-\mathrm{H} 5 \mathrm{~b} \cdots \mathrm{O} 1$, (d) $\mathrm{C} 9-\mathrm{H} 9 \mathrm{c} \cdots \mathrm{O} 2+$ $\mathrm{C} 7-\mathrm{H} 7 \mathrm{~b} \cdots \pi(\mathrm{N} 1, \mathrm{~N} 2, \mathrm{C} 1-\mathrm{C} 4)$ and (e) inter-layer $\mathrm{C} 5-\mathrm{H} 5 \mathrm{a} \cdots \mathrm{N} 2$ interactions.

\subsection{Energy framework simulation and crystal lattice energy calculation}

With the absence of conventional hydrogen bonds, the crystal of $\mathbf{1}$ is governed primarily by dispersion forces mainly attributed to the $\pi \cdots \pi$ and other weak interactions. As shown in Fig. 9, this leads to a shield-like dispersion force topology which supersedes the electrostatic forces. The combination of the electrostatic and dispersion forces leads to the same topology without much variation. 

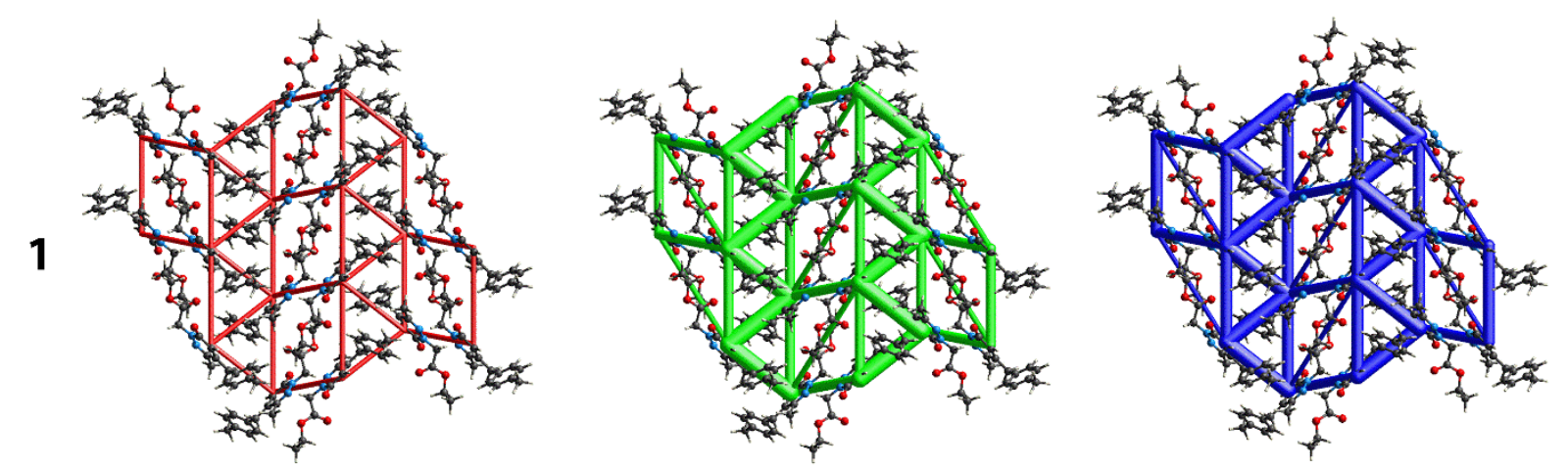

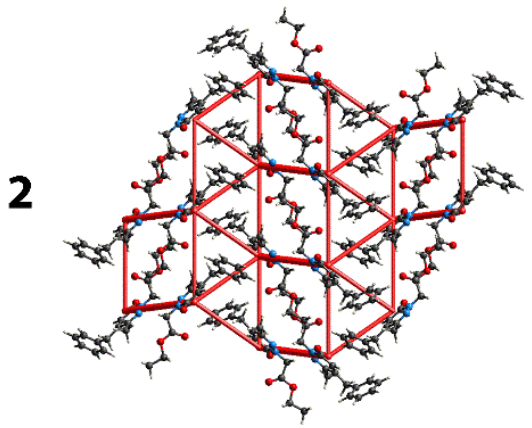

(a)

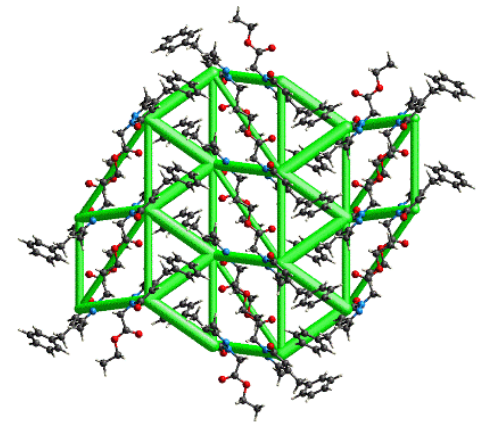

(b)

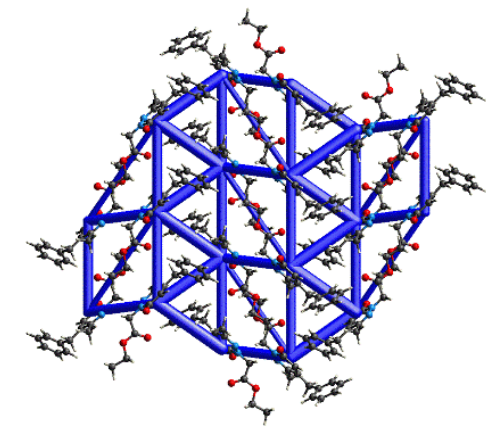

(c)

Fig. 9. The calculated energy frameworks for $\mathbf{1}$ and $\mathbf{2}$ as viewed along the a-axis, showing the (a) electrostatic force (red cylinders), (b) dispersion force (green) and (c) total energy (blue) diagrams. The cylindrical radius is proportional to the relative strength of the corresponding energies and they were adjusted to the same scale factor of 150 with a cut-off value of 1.9 $\mathrm{kcal} / \mathrm{mol}$ within a $2 \times 2 \times 1$ unit-cells.

The crystal of $\mathbf{2}$ exhibits a similar topographical profile as for $\mathbf{1}$ owing to their comparable molecular packing. Nevertheless, the greater electrostatic and dispersion forces are evident in $\mathbf{1}$ compared to $\mathbf{2}$ as can be discerned from the relatively thicker energy frameworks suggesting that greater stabilisation energy exists in 1. These qualitative observations are vindicated by quantitative lattice energy calculations which confirm the lattice energy calculated for 1 , i.e. $-29.9 \mathrm{kcal} / \mathrm{mol}$, is about $4.1 \mathrm{kcal} / \mathrm{mol}$ more stable than that calculated for 2, Table 9. This suggests the inclusion of methyl substituent in the structural framework of 1 plays an essential role in stabilising the overall molecular packing. 


\section{Table 9}

The lattice energy $\left(E_{\text {lattice}}\right)$ and the corresponding energy components $\left(E_{\text {electrostatic }}, E_{\text {polarization, }}\right.$ $E_{\text {dispersion }}$ and $\left.E_{\text {repulsion}}\right)$ calculated for a cluster of molecules within $25 \AA$ from a reference molecule through the CE-B3LYP/6-31G $(d, p)$ model. All values are expressed as $\mathrm{kcal} / \mathrm{mol}$.

\begin{tabular}{ccccccc}
\hline Compound & $E_{\text {electrostatic }}$ & $E_{\text {polarization }}$ & $E_{\text {dispersion }}$ & $E_{\text {repulsion }}$ & $E_{\text {total }}$ & $E_{\text {lattice }}$ \\
\hline $\mathbf{1}$ & -24.4 & -6.1 & -56.2 & 26.8 & -59.8 & -29.9 \\
$\mathbf{2}$ & -20.8 & -5.2 & -49.5 & 23.7 & -51.9 & -26.0 \\
\hline
\end{tabular}

\subsection{Packing similarity study}

The packing similarity was performed in Mercury [68] to differentiate the packing arrangements in the crystals of $\mathbf{1}$ and $\mathbf{2}$. The analysis shows that both crystals have some similarities in term of their molecular packing, with six out of 15 pairs of molecules found to meet the $20 \%$ tolerance criterion in both distance and angle deviations and overlap, Supplementary Materials Fig. S7. The r.m.s. deviation for the overlap is about $0.39 \AA$. While 1 and 2 have the same structural framework, major deviations in the precise molecular packing are evident.

\subsection{Biological activities}

\subsubsection{Enzyme inhibitory activity: $\alpha$-Glucosidase inhibition assay}

Compound $\mathbf{1}$ was tested for its potential inhibitory activity against the enzyme $\alpha$-glucosidase with the obtained results are listed in Table 10. The inhibitory activity of $\mathbf{1}$ was tested at two different concentrations, i.e. 22.5 and $45 \mathrm{mM} / 1$. Compound 1 exhibited a moderate inhibition potential activity against $\alpha$-glucosidase comparing to Acarbose which is the reference employed in this study. The percentage of inhibition for Acarbose at $22 \mathrm{mM} / 1$ is two times 
higher than 1 at $45.0 \mathrm{mM} / 1$. The increase of concentration of $\mathbf{1}$ in the assay from 22.5 to 45.0 $\mathrm{mM} / 1$ increased the inhibitory percentage by less than $15 \%$.

\section{Table 10}

The inhibitory effects of $\mathbf{1}$ and Acarbose against the enzyme $\alpha$-glucosidase

\begin{tabular}{|c|c|c|}
\hline \multirow{2}{*}{$\mathbf{1}$} & concentrations (mM/l) & $\alpha$-glucosidase inhibition (\%) \\
& 22.5 & 32.20 \\
\cline { 2 - 3 } & 45 & 47.98 \\
\hline Acarbose & 20 & 90.60 \\
\hline
\end{tabular}

\subsubsection{In vitro anti-inflammatory study: Heat-induced haemolysis}

Compound 1 was also evaluated for its in vitro potential anti-inflammatory activity by heatinduced haemolysis. The results summarised in Table 11 showed that $\mathbf{1}$ exerts low heatinduced haemolysis inhibition. When 1 was tested at different concentrations, i.e. 250, 500 and $1000 \mathrm{mM} / 1$, and the results compared to Indomethacin and Aspirin at $100 \mathrm{mM} / \mathrm{l}$, which were the reference compounds in the assay. The percentage of inhibition of 1 at $1000 \mathrm{mM} / 1$ is two times less than Aspirin at $100 \mathrm{mM} / 1$. The increase of concentration of product from 250 to $1000 \mathrm{mM} / 1$ had a weak effect on the increase of heat-induced heaemolysis inhibition percentage, i.e. less than a $4 \%$ increase.

\section{Table 11}

Effect of 1, Indomethacin and Aspirin on heat induced haemolysis of erythrocyte.

\begin{tabular}{|c|c|c|}
\hline & concentrations (mM/l) & $\alpha$-glucosidase inhibition (\%) \\
\hline \multirow{2}{*}{$\mathbf{1}$} & 250 & 15.22 \\
\cline { 2 - 3 } & 500 & 18.14 \\
\hline
\end{tabular}




\begin{tabular}{|c|c|c|}
\hline & 1000 & 18.74 \\
\hline Indomethacin & 100 & 27.01 \\
\hline Aspirin & 100 & 34.75 \\
\hline
\end{tabular}

Great attention has been paid to compounds containing a pyridazin-3(2H)-one moiety, due to their potential biological activities, such as anti-inflammatory [1-8]. Structure-activity relationship studies showed that the alkylation of the lactame function of pyridazin-3(2H)-one improves this activity, in agreement with the results obtained for $\mathbf{1}$. On the other hand, a series of pyridazine analogues was prepared and their potency against $\alpha$-glucosidase was investigated by Chaudhry et al. [9]. The ring-bound oxygen atom forms a hydrogen bonding interaction with the $\alpha$-glucosidase residue Asn246. Also, the substituents in the N-phenyl ring were also important factors [10]. The nature and positional effects of substituents were also found highly significant. These interactions and N-alkylation by 2-ethyl bromoacetate make $\mathbf{1}$ more potent: it could be a promising candidate for more potent anti-diabetic drugs.

\section{Conclusions}

Crystallography on a new pyridazinone derivative, 1, shows a planar pyridazinyl ring consistent with significant delocalisation of $\pi$-electron density over the ring. A kink observed in the conformation of the ethylacetate group does not persist in the optimised, gas-phase structure, 1g. The phenyl analogue of 1, namely 2, exhibits experimental and theoretical structures consistent with $\mathbf{1 g}$. Despite this, the molecular packing of $\mathbf{1}$ and $\mathbf{2}$ are distinct with differences primarily traced to the influence of the methyl group in $\mathbf{1}$ which results in a more stable overall molecular packing in $\mathbf{1}$, by ca $4.1 \mathrm{kcal} / \mathrm{mol}$. Compound $\mathbf{1}$ shows moderate inhibition in an assay conducted toward $\alpha$-glucosidase and a weak inhibition towards heatinduced haemolysis. 


\section{Declaration of competing interest}

The authors of this manuscript declare no conflict of interest.

\section{Author contributions}

Younes Zaoui:

Youssef Ramli:

Sang Loon Tan: Performed the computational chemistry analysis, Wrote a draft the paper.

Edward R. T. Tiekink: Performed the X-ray crystallographic analysis, Wrote the paper.

Laila Chemlal:

Joel T. Mague: Collected and processed the X-ray data

Jamal Taoufik:

M.A.Faouzi:

M'Hammed Ansar:

\section{Acknowledgements}

The support of NSF-MRI Grant \#1228232 for the purchase of the diffractometer and Tulane University for support of the 105 Tulane Crystallography Laboratory are gratefully acknowledged. Sunway University Sdn Bhd is also thanked for funding (Grant. no. STRRCTR-RCCM-001-2019).

Appendix A. Supplementary data

Supplementary data to this article can be found online at https://doi.org/10.1016/j.molstruc.2021. 


\section{References}

[1] D. Tiryaki, M. Sukuroglu, D.S. Dogruer, E. Akkol, S. Ozgen, M.F. Sahin, Synthesis of some new 2,6-disubstituted-3(2H)-pyridazinone derivatives and investigation of their analgesic, anti-inflammatory and antimicrobial activities, Med. Chem. Res. 22 (2013) 2553-2560.

[2] E. Banoglu, Ç. Akoğlu, S. Ünlü, E. Küpeli, E. Yeşilada, M.F. Şahin, Amide derivatives of [6-(5-methyl-3-phenylpyrazole-1-yl)-3(2h)-pyridazinone-2-yl]acetic acids as potential analgesic and anti-inflammatory compounds, Arch. Pharm. Chem. Life Sci. 337 (2004) 7-14.

[3] S. Baytaş, N. İnceler, K.F. Mavaneh, M.O. Uludağ, N. Abacioğlu, M. Gökçe, Synthesis of antipyrine/pyridazinone hybrids and investigation of their in vivo analgesic and antiinflammatory activities, Turk. J. Chem. 36 (2012) 734-748.

[4] D.G.H. Livermone, R.C. Bethell, N. Cammack, A.P. Hancock, M.M. Hann, D.V.S. Green, R.B. Lamont, S.A. Noble, D.C. Orr, J.J. Payne, M.V.J. Ramsay, A.H. Shingler, C. Smith, R. Storer, C. Williamson, T. Willson, Synthesis and anti-HIV-1 activity of a series of imidazo[1,5-b]pyridazines, J. Med. Chem. 36 (1993) 3784-3794.

[5] D. Csókás, I. Zupkó, B.I. Károlyi, L. Drahos, T. Holczbauer, A. Palló, M. Czugler, A. Csámpai, Synthesis, spectroscopy, X-ray analysis and in vitro antiproliferative effect of ferrocenylmethylene-hydrazinylpyridazin-3(2H)-ones and related ferroceno[d]pyridazin-1(2H)-ones, J. Organomet. Chem. 743 (2013) 130-138.

[6] P. Nagle, Y. Pawar, A. Sonawane, S. Bhosale, D. More, Docking simulation, synthesis and biological evaluation of novel pyridazinone containing thymol as potential antimicrobial agents, Med. Chem. Res. 23 (2014) 918-926. 
[7] M.A. El-Hashash, D.B. Guirguis, N.A.M.A. El-Wahed, M.A. Kadhim, Synthesis of novel series of phthalazine derivatives with antibacterial and antifungal evaluation, J. Chem. Eng. Process Technol. 5 (2014) article number 1000195.

[8] B. Sharma, A. Verma, U.K. Sharma, S. Prajapati, Efficient synthesis, anticonvulsant and muscle relaxant activities of new 2-((5-amino-1,3,4-thiadiazol-2-yl)methyl)-6-phenyl4,5-dihydropyridazin-3(2H)-one derivatives, Med. Chem. Res. 23 (2014) 146-157.

[9] D.W. Robertson, J.H. Krushinski, B.G. Utterback, R.F. Kauffman, Synthesis of a tritiumlabeled indolidan analog and its use as a radioligand for phosphodiesterase-inhibitor cardiotonic binding sites, J. Med. Chem. 32 (1989) 1476-1480.

[10] T. Yamada, H. Shimamura, Y. Tsukamoto, A. Yamaguchi, M. Ohki, Pyridazinones. 3. Synthesis, antisecretory, and antiulcer activities of 2-cyanoguanidine derivatives, $\mathrm{J}$. Med. Chem. 26 (1983) 1144-1149.

[11] S. Demirayak, A.C. Karaburun, R. Beis, Some pyrrole substituted aryl pyridazinone and phthalazinone derivatives and their antihypertensive activities, Eur. J. Med. Chem. 39 (2004) 1089-1095.

[12] P. Mátyus, J. Kosáry, E. Kasztreiner, N. Makk, E. Diesler, K. Czakó, G. Rabloczky, L. Jaszlits, E. Horváth, Z. Tömösközi, G. Cseh, E. Horváth, P. Arányi, Synthesis, antihypertensive and $\alpha$-adrenoceptor activity of novel 2-aminoalkyl-3(2H)pyridazinones, Eur. J. Med. Chem. 27 (1992) 107-114.

[13] T. Shono, M. Takahashi, T. Umehara, In Proceedings of the 1st International Conference on Insect Pests in the Urban Environment (1993) 123-124.

[14] P. Lümmen, Complex I inhibitors as insecticides and acaricides, Biochim. Biophys. Acta 1364 (1998) 287-296.

[15] M.A. Dekeyser, Acaricide mode of action, Pest Manag. Sci. 61 (2005) 103-110. 
[16] J.L. Hilton, A.L. Scharen, J.B. John, D.E. Moreland, K.H. Norris, Modes of action of pyridazinone herbicides, Weed Sci. 17 (1969) 541-547.

[17] G.A. Bean, A. Southall, Effect of pyridazinone herbicides on growth and aflatoxin release by Aspergillus flavus and Aspergillus parasiticus, Appl. Environ. Microbiol. 46 (1983) 503-505.

[18] Y. Boukharsa, Y. Zaoui, J. Taoufik, and M. Ansar, Pyridazin-3(2H)-ones: Synthesis, reactivity, applications in pharmacology and agriculture, J. Chem. Pharm. 46 (2015) 297.

[19] N. Bouchmaa, R. Ben Mrid, Y. Boukharsa, M. Nhiri, H. Ait Mouse, J. Taoufik, M. Ansar, A. Zyad, Cytotoxicity of new pyridazin-3(2H)-one derivatives orchestrating oxidative stress in human triple-negative breast cancer (MDA-MB-468), Arch. Pharm. Chem. Life Sci. 351 (2018) article number e1800128.

[20] W. Guerrab, H. Lgaz, S. Kansiz, J.T. Mague, N. Dege, M. Ansar, R. Marzouki, J. Taoufik, I.H. Ali, I-M. Chung, Y. Ramli, Synthesis of a novel phenytoin derivative: Crystal structure, Hirshfeld surface analysis and DFT calculations, J. Mol. Struct. 1205 (2020) article number 127630.

[21] Y. Ramli, E.M. Essassi, Condensation study of hydrazonoyl chloride with 3methylquinoxalin-2-one and 3-styrylquinoxalin-2-one, J. Mar. Chim. Heterocycl. 18 (2019) 39-47.

[22] Y. Zaoui, Y. Ramli, J. Taoufik, J.T. Mague, M.M. Jotani, E.R.T. Tiekink, M. Ansar, Ethyl 2-(4-benzyl-3-methyl-6-oxo-1,6-di-hydropyridazin-1-yl)acetate: crystal structure and Hirshfeld surface analysis, Acta Crystallogr. E75 (2019) 392-396.

[23] Y. Boukharsa, W. Lakhlili, J. El harti, B. Meddah, R. Y. Tiendrebeogo, J. Taoufik, M. E. A. Faouzi, A. Ibrahimi, M. Ansar, Synthesis, anti-inflammatory evaluation in vivo and 
docking studies of some new 5-(benzo[b]furan-2-ylmethyl)-6-methyl-pyridazin-3(2H)one derivatives, J. Mol. Struct. 1153 (2018) 119-127.

[24] M. El-Fal, K. Sayah, I. Marmouzi, M.E.A. Faouzi, M. Ansar, J. Taoufik, E.M. Essassi, Y. Ramli, Synthesis, and evaluation of $\alpha$-amylase and $\alpha$-glucosidase inhibitory potential of new pyrazolo[3,4- $d$ ]pyrimidine derivatives, Eur. J. Chem. 8 (2017) 105-108.

[25] Y. El Bakri, E.H. Anouar, I. Marmouzi, K. Sayah, Y. Ramli, M.E.A. Faouzi, E.M. Essassi, J.T. Mague, Potential antidiabetic activity and molecular docking studies of novel 3ynthesized 3.6-dimethyl-5-oxo-pyrido[3,4-f][1,2,4]triazepino[2,3a]benzimidazole and 10-amino-2-methyl-4-oxo pyrimido[1,2-a]benzimidazole derivatives, J. Mol. Model. 24 (2018) article number 179.

[26] SAINT \& SADABS, Bruker. Madison, WI (2016).

[27] G.M. Sheldrick, A short history of SHELX, Acta Crystallogr. A64 (2008) 112-122.

[28] G.M. Sheldrick, Crystal structure refinement with SHELXL, Acta Crystallogr. C71 (2015) 3-8.

[29] L.J. Farrugia, WinGX and ORTEP for Windows: an update, J. Appl. Crystallogr. 45 (2012) 849-854.

[30] DIAMOND, Visual Crystal Structure Information System, Version 3.1, CRYSTAL IMPACT, Postfach 1251, D-53002 Bonn, Germany, (2006).

[31] A.L. Spek, CheckCIF validation ALERTS: what they mean and how to respond, Acta Crystallogr. E76 (2020) 1-11.

[32] M.J. Frisch et al., Gaussian 16, Revision A.03, Gaussian, Inc., 2016. Wallingford, Connecticut, USA.

[33] J.J. Stewart, Optimization of parameters for semiempirical methods VI: more modifications to the NDDO approximations and re-optimization of parameters, J. Mol. Model. 19 (2013) 1-32. 
[34] F. Weigend, R. Ahlrichs, Balanced basis sets of split valence, triple zeta valence and quadruple zeta valence quality for H to Rn: Design and assessment of accuracy, Phys. Chem. Chem. Phys.7 (2005) 3297-3305.

[35] J.E. Carpenter, F. Weinhold, Analysis of the geometry of the hydroxymethyl radical by the "different hybrids for different spins" natural bond orbital procedure, J. Mol. Struct. (Theochem) 169 (1988) 41-62.

[36] R. Dennington, T.A. Keith, J.M. Millam, GaussView, Version 6, Semichem Inc., 2016. Shawnee Mission, Kansas, USA.

[37] P. Fuentealba, P. Pérez, R. Contreras, On the condensed Fukui function, J. Chem. Phys. 113 (2000) 2544-2551.

[38] C. Morell, A. Grand, A. Toro-Labbé, New dual descriptor for chemical reactivity, J. Phys. Chem. A 109 (2005) 205-212.

[39] C. Morell, A. Grand, A. Toro-Labbé, Theoretical support for using the $\Delta f(r)$ descriptor, Chem. Phys. Lett. 425 (2006) 342-346.

[40] M.J. Turner, J.J. Mckinnon, S.K. Wolff, D.J. Grimwood, P.R. Spackman, D. Jayatilaka, M.A. Spackman, CrystalExplorer 17.5, 2017, The University of Western Australia.

[41] S.L. Tan, M.M. Jotani, E.R.T. Tiekink, Utilizing Hirshfeld surface calculations, noncovalent inter-action (NCI) plots and the calculation of interaction energies in the analysis of molecular packing, Acta Crystallogr. E75 (2019) 308-318.

[42] M.A. Spackman, D. Jayatilaka, Hirshfeld surface analysis, CrystEngComm 11 (2009) 1932.

[43] M.A. Spackman, J.J. McKinnon, Fingerprinting intermolecular interactions in molecular crystals, CrystEngComm 4 (2002) 378-392. 
[44] J. Contreras-García, E.R. Johnson, S. Keinan, R. Chaudret, J.P. Piquemal, D.N. Beratan, W. Yang, NCIPLOT: A program for plotting noncovalent interaction regions, J. Chem. Theory Comput. 7 (2011) 625-632.

[45] E.R. Johnson, S. Keinan, P. Mori-Sánchez, J. Contreras-García, A.J. Cohen, W. Yang, Revealing noncovalent interactions, J. Am. Chem. Soc. 132 (2010) 6498-6506.

[46] W. Humphrey, A. Dalke, K. Schulten, VMD: Visual molecular dynamics, J. Mol. Graph. $14(1996) 33-38$.

[47] M.J. Turner, S. Grabowsky, D. Jayatilaka, M.A. Spackman, Accurate and efficient model energies for exploring intermolecular interactions in molecular crystals, J. Phys. Chem. Lett. 5 (2014) 4249-4255.

[48] C.F. Mackenzie, P.R. Spackman, D. Jayatilaka, M.A. Spackman, CrystalExplorer model energies and energy frameworks: extension to metal coordination compounds, organic salts, solvates and open-shell systems, IUCrJ 4 (2017) 575-587.

[49] S.P. Thomas, P.R. Spackman, D. Jayatilaka, M.A. Spackman, Accurate lattice energies for molecular crystals from experimental crystal structures, J. Chem. Theory Comput. 14 (2018) 1614-1623.

[50] K.T. Kee, M. Koh, L.X. Ong, K. Ng, Screening culinary herbs for antioxidant and $\alpha-$ glucosidase inhibitory activities, Int. J. Food Sci. Technol. 48 (2013) 1884-1891.

[51] U.A. Shinde, A.S. Phadke, A.M. Nari, A.A. Mungantiwar, V.J. Dikshit, M.N. Saraf, Membrane stabilizing activity - a possible mechanism of action for the antiinflammatory activity of Cedrus deodara wood oil, Fitoterapia 70 (1999) 251-257.

[52] E. Umapathy, E.J. Ndebia, A. Meeme, B. Adam, P. Menziwa, B. N. Nkeh-Chungag, J.E. Iputo, An experimental evaluation of Albuca setosa aqueous extract on membrane stabilization, protein denaturation and white blood cell migration during acute inflammation, J. Med. Plants Res. 4 (2010) 789-795. 
[53] C.O. Okoli, P.A. Akah, N.J. Onuoha, T.C. Okoye, A.C. Nwoye, C.S. Nworu, Acanthus montanus: An experimental evaluation of the antimicrobial, anti-inflammatory and immunological properties of a traditional remedy for furuncles, BMC Complement. Altern. Med 8 (2008) article number 27.

[54] P. Ranasinghe, P. Ranasinghe, W.P.K.M. Abeysekera, G.A.S. Premakumara, Y.S. Perera, P. Gurugama, S.B. Gunatilake, In vitro erythrocyte membrane stabilization properties of Carica papaya L. leaf extracts, Pharmacogn. Res. 4 (2012) 196-202.

[55] R. Tandon, T.A. Nigst, H. Zipse, Inductive effects through alkyl groups - how long is long enough? Eur. J. Org. Chem. 2013 (2013) 5423-5430.

[56] P. Matczak, A test of various partial atomic charge models for computations on diheteroaryl ketones and thioketones, Computation 4 (2016) article number 3.

[57] J. Rigby, E.I. Izgorodina, Assessment of atomic partial charge schemes for polarisation and charge transfer effects in ionic liquids, Phys. Chem. Chem. Phys. 15 (2013) 16321646.

[58] V. Nikolova, D. Cheshmedzhieva, S. Ilieva, B. Galabov, Atomic charges in describing properties of aromatic molecules, J. Org. Chem. 84 (2019) 1908-1915.

[59] S. Liu, Where does the electron go? The nature of ortho/para and meta group directing in electrophilic aromatic substitution, J. Chem. Phys. 141 (2014) article number 194109.

[60] R.G. Parr, W. Yang, Density-functional theory of the electronic structure of molecules, Ann. Rev. Phys. Chem. 46 (1995) 701-728.

[61] H. Chermette, Chemical reactivity indexes in density functional theory, J. Comput. Chem. 20 (1999) 129-154.

[62] P. Geerlings, F.D. Proft, W. Langenaeker, Conceptual density functional theory, Chem. Rev. 103 (2003) 1793-1874. 
[63] E. Echegaray, C. Cárdenas, S. Rabi, N. Rabi, S. Lee, F.H. Zadeh, A. Toro-Labbe, J.S. M. Anderson, P.W. Ayers, In pursuit of negative Fukui functions: examples where the highest occupied molecular orbital fails to dominate the chemical reactivity, J. Mol. Model. 19 (2013) 2779-2783.

[64] J.I. Martínez-Araya, Why is the dual descriptor a more accurate local reactivity descriptor than Fukui functions? J. Math. Chem. 53 (2015) 451-465.

[65] K.B. Wiberg, Application of the pople-santry-segal CNDO method to the cyclopropylcarbinyl and cyclobutyl cation and to bicyclobutane, Tetrahedron 24 (1968) 1083-1096.

[66] A.E. Reed, L.A. Curtiss, F. Weinhold, Intermolecular interactions from a natural bond orbital, donor-acceptor viewpoint, Chem. Rev. 88 (1988) 899-926.

[67] K. Molčanov, B. Kojić-Prodić, Towards understanding $\pi$-stacking interactions between non-aromatic rings, IUCrJ 6 (2019) 156-166.

[68] C.F. Macrae, I. Sovago, S.J. Cottrell, P.T. A. Galek, P. McCabe, E. Pidcock, M. Platings, G.P. Shields, J.S. Stevens, M. Towler, P.A. Wood, Mercury 4.0: from visualization to analysis, design and prediction, J. Appl. Cryst. 53 (2020) 226-235. 